Research Article

\title{
Design of High-Power High-Efficiency Wireless Charging Coils for EVs with MnZn Ferrite Bricks
}

\author{
Yuyu Zhu $\mathbb{D}^{\text {, }}$, Zuming Wang ${ }^{\mathbb{D}}$, Xin Cao $\mathbb{D}^{\mathbb{D}}$, and Li Wu \\ School of Information Engineering, Southwest University of Science and Technology, Mianyang 621010, China \\ Correspondence should be addressed to Xin Cao; caoxin@swust.edu.cn
}

Received 30 March 2021; Revised 16 August 2021; Accepted 5 October 2021; Published 25 October 2021

Academic Editor: Bin Gao

Copyright (c) 2021 Yuyu Zhu et al. This is an open access article distributed under the Creative Commons Attribution License, which permits unrestricted use, distribution, and reproduction in any medium, provided the original work is properly cited.

\begin{abstract}
In wireless power transmission systems, the inductance, equivalent resistance, and quality factors of the coils are the main factors that influence the system's transmission efficiency. When designing high-power wireless charging coils for electric vehicles (EVs), ferrite bricks that increase magnetic flux can be selected to increase the self-inductance of the coils, improving the wireless transmission distance and transmission efficiency. In this paper, the effects of the ferrite bricks, the size of the coils, the charging distance, and many other factors in real applications have been extensively studied. After theoretical analysis and simulation, the wireless transmission system has been fabricated and measured. The measured and simulated results are in good agreement. High-power high-efficiency wireless power transmission has been achieved for EVs compared with many other previous literatures.
\end{abstract}

\section{Introduction}

A wired method as a traditional power transmission method will inevitably cause line loss during power transmission. At the same time, problems such as line aging and cuttingedge discharge greatly reduce the reliability and safety of wired power transmission, shortening the service life of the equipment. On the one hand, on special occasions such as mines and seabeds, traditional wired power supply can sometimes cause fatal problems. In some even severe cases, it may also cause explosions, fires, etc., bringing great safety hazards and economic losses. On the other hand, the power supply of a large number of electrical appliances can cause the crossing of various power lines, which can bring great inconvenience to people's lives. Therefore, wireless power transmission has been the goal that mankind has pursued tirelessly [1-3].

The magnetic coupling resonant wireless power transmission system can achieve large-distance transmission because of the high-quality factors of the transmitting and receiving coils and the effective coupling in between. Therefore, designing a coil with high-quality factors is the key to system design. In the design of the electric vehicle wireless power transmission coupling mechanism, in order to increase the transmission power, enhance the coupling coefficient, and reduce the magnetic field leakage, the ferrite structure is usually used to increase the coils' selfinductance and restrict the surrounding magnetic flux to a confined space. In order to reduce the volume of the entire structure, flat ferrite magnetic sheets are usually selected and placed near the coils.

$[4,5]$ proposed a solenoid double-sided winding structure suitable for $3 \mathrm{~kW}$ wireless charging of electric vehicles. The original structure was then optimized and improved to the $\mathrm{H}$-shaped structure, and $90 \%$ efficiency wireless power transmission was realized under the condition of a transmission distance of $20 \mathrm{~cm}$. Based on the coil structure, a Hc-type magnetic core winding structure was proposed in [6]. The Hc-type magnetic core winding structure can achieve good coupling with the circular or $\mathrm{H}$-shaped coil structure, which means this structure has better compatibility. In order to increase the output power of the system, [7] proposed an aluminum bracket with cooling on the basis of a solenoid double-sided winding structure, so that the output power can reach $10 \mathrm{~kW}$. However, this structure has many windings and high line loss, which limits the improvement of transmission efficiency to a certain extent. [8] proposed a 
single-coil electromagnetic coupling mechanism. Through simulation, the line width of the coil and the distribution and number of magnetic cores were studied, and the optimal design plan was established. However, under the same coil area, although the circular coil has a larger coupling coefficient, in practical applications, the square coil can more effectively use the space of the vehicle chassis, thereby obtaining a higher coupling coefficient. In order to improve the coupling coefficient of the coil, the flux pipe structure was proposed [2]. This design makes the coil have a better horizontal deflection capability, because the coil is wound by a solenoid. The magnetic core increases the magnetic flux path, so that the transmission distance of the two coils is increased to half the size of the original side, which increases the transmission distance. But this structure also increases additional losses and is not easy to install. Therefore, the DD-type and DDQ-type coil structures were proposed in [2]. DD-type coil was used as the transmitting coil and the DDQ-type coil as the receiving coil. The induction blind spot was avoided by controlling the phase of the two coil currents, so that the charging area is increased by 4 times. $[9,10]$ proposed a BBP-type coil structure with two square coils placed crosswise to replace the DDQ-type coil, which reduces the wire consumption by $25.17 \%$. [11] proposed a TTP-type coil structure with three coils symmetrically superimposed. The coils were improved by the voltage amplitude and phase relationship of each coil and the offset capability. [12] proposed a three-coil structure with a relay coil in the middle of the transmitting coil. The front of the coil adopts series resonance. When the transmission distance is $100 \mathrm{~mm}$, the output power is $1 \mathrm{~kW}$, and the transmission efficiency reaches $91.3 \%$. However, in general, the multicoil structure increases the number of inverters required to drive the coils, which not only complicates the control but also increases the cost of the system.

In order to increase the coupling coefficient of the coupling mechanism, [13] proposed a three-coil electric vehicle wireless charging coupling mechanism. The small coil improves the transmission efficiency of the system. The receiving coil is much smaller than the transmitting coil. This coupling mechanism greatly increases the antibias of the coil. It also has a good electromagnetic shielding effect. However, although adding a small middle coil can improve the transmission efficiency, it will produce obvious frequency splitting, and the output will be unstable for a system with wide load changes. In order to avoid the frequency splitting coil, the coil design will become complex. [14] proposed a regular tetrahedral electric energy pick-up mechanism for the multidegree-of-freedom pick-up problem of a magnetic coupling resonance wireless power transmission system. When rotating at any angle, it can maintain the load power at $30 \mathrm{~W}$ and the transmission efficiency at $60 \%$. The DLDD coils were used as the transmitting and receiving coil for static wireless charging of electric vehicles. This coil design has good antioffset ability. When the coil size is 60 $\mathrm{cm} \times 60 \mathrm{~cm}$ and the horizontal offset is $20 \mathrm{~cm}$, the transmission efficiency is still $82.3 \%$. Based on the transformer's magnetic circuit model and flux classification method, $[15,16]$ calculated the relationship between the magnetic resistance and coupling coefficient of each part of the transformer and proposed a noncontact transformer coil structure. The coils adopted a figure-eight winding method, and two large-area magnetic cores provided a low magnetic resistance loop. The solenoid winding coil to the central column of the magnetic core increased the coupling coefficient of the two coils and reduced the size of the coupling mechanism, so that the charging efficiency applied to ZTE new energy vehicles was higher than 90\%. [17] uses the method of parameter solving to calculate the overall change trend of the space magnetic field and circuit parameters of singleturn coils with different radii and proposed five groups of parallel-wound disk-shaped coil structures. The transmitting coil was excited by a voltage source. The wireless power transmission system had an interval of $300 \mathrm{~mm}$, a resonance frequency of $212 \mathrm{kHz}$, an output power of $3 \mathrm{~kW}$, and a system transfer efficiency of $92.5 \%$ [18]. However, the transmitter coil was large in size and difficult to wind, and it is not easy to install.

At present, the wireless power transmission coils used in electric vehicles are mainly planar spiral coils, but the design steps for a single planar spiral coil are relatively vague, especially for the requirements of higher power levels, and the design cannot be made from the perspective of wireless power transmission coils. There are few researches on coils with asymmetric structures. Although the asymmetric structure reduces the coupling coefficient of the two coils to a certain extent, the gain of the antioffset ability of the coil is notable. In the case of limited coil size, the asymmetric structure can be simple and effectively increase the antioffset ability of the two coils.

In order to ensure the safety of the electromagnetic environment of the surrounding environment during the power transmission process, electromagnetic shielding of the transmission coil is required to confine the space energy as much as possible to the limited space in the two coils, and the impact on the outside of the functional working area should be minimized. Therefore, it is necessary to use materials with high permeability and low loss characteristics for reasonable electromagnetic shielding design, and its material and size need to be designed and optimized. At present, the research on magnetic shielding materials is mainly on the material, and there is a lack of complete research on the size of magnetic shielding materials. The size has an impact on the relevant parameters of the coil, including inductance, AC equivalent resistance, and distributed capacitance. The design of the size of the magnetic shielding material also lacks relevant design basis.

This paper focuses on the research on the parameter design and energy efficiency characteristics of the electric vehicle wireless power transmission coil and solves the current problem of ambiguity in the design of a highpower single plane spiral coil. From the perspective of coil design, consider the shape, size, wire diameter, and turn of a single plane spiral coil. Considering the factors such as the number and turn spacing, we have designed a wireless power transmission coil that meets a specific power level and efficient transmission. In order to maximize the antioffset ability of the coil under the size limit, we also have 


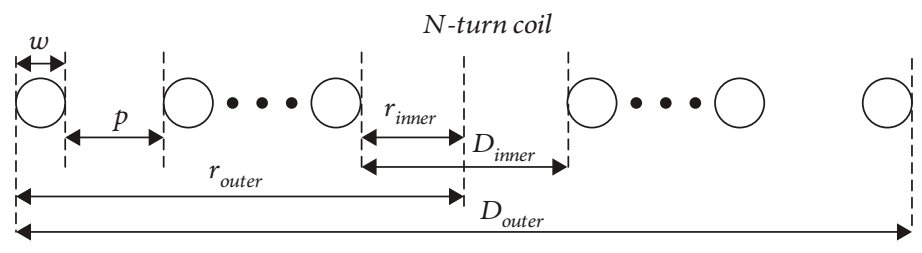

Figure 1: Cross-section schematic diagram of a planar spiral coil.

analyzed the coil coupling coefficient and transmission of the asymmetric structure. The design method of the coil when adopting an asymmetric structure is given. The magnetic shielding material with high permeability and low loss and suitable for electric vehicle wireless charging systems also needs to optimize its design size. The influence of the magnetic shield size on the inductance, AC equivalent resistance, and distributed capacitance of the coil is studied, and the design basis of the magnetic shield size is given.

\section{Theory and Design Process}

Wheeler proposed several plane spiral formulas applied to separate inductors. Mohan improved the original Wheeler formula and got the improved Wheeler formula, which can effectively calculate the inductance of the plane spiral integrated inductor. The improved Wheeler formula is given as [19]

$$
L=\frac{N^{2}\left(D_{\text {outer }}-N(w+p)\right)^{2}}{16 D_{\text {outer }}+28 N(w+p)} \times \frac{39.37}{10^{6}}(H),
$$

where $N$ is the number of turns, $w$ is the diameter of the wire, $p$ is the spacing between the wires, and $D_{\text {outer }}$ is the outer diameter of the coil, as shown in Figure 1.

The distributed capacitance of the coil cannot be ignored under high-frequency working environment. The equivalent model of the distributed capacitance of the coil is shown in Figure 2.

It can be seen that the distributed capacitance can be equivalent to the form of series cascading, so the distributed capacitance of the coil is

$$
C_{p}=\frac{1}{n-1} C_{i, j}(i=1 \cdots n-1, j=i+1)
$$

where $C_{p}$ represents the distributed capacitance of the coil, $C_{i, j}$ represents the distributed capacitance between two adjacent turns, and $n$ represents the number of turns of the coil.

In practical applications, the wires of the coil are mostly round wires. Therefore, the simplified turn-to-turn capacitance model is shown in Figure 3. The radius of the litz wire used by the coil is $r$, the length is $l$, and the center distance between two adjacent turns is $P . C_{\text {gap }}$ is the distributed capacitance between two adjacent turns of the coil. The distributed capacitance between two adjacent turns can be calculated as

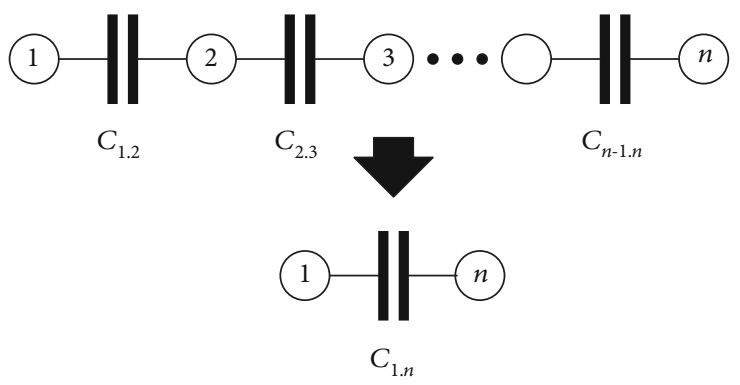

FIgURE 2: Schematic diagram of equivalent distributed capacitance of coil.

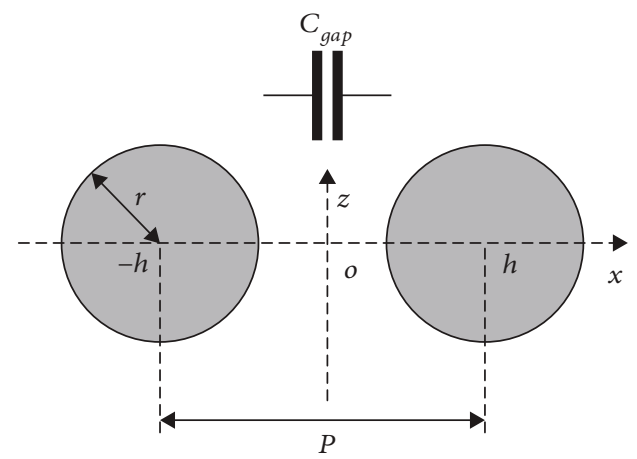

FIgURE 3: Distributed capacitance model between turns.

$$
C_{\text {gap }}=\frac{\pi \varepsilon l}{\ln \left[P / 2 r+\sqrt{(P / 2 r)^{2}-1}\right]}=\frac{\pi \varepsilon l}{\operatorname{arcosh}(P / 2 r)},
$$

where $\varepsilon$ represents the dielectric constant of air.

The AC equivalent resistance $R_{\mathrm{AC}}$ of the nonclose wound planar spiral receiving coil can be calculated by formula (5), where $R_{\mathrm{DC}}$ can be calculated by formula (6). In the formulas, $l$ is the length of the coil wire, $r$ is the winding radius, and $\sigma$ is the conductivity of the wire:

$$
\begin{gathered}
l=4 \sum_{1}^{N}\left(D_{\text {inner }}+2 \times N \times(w+P)\right), \\
R_{\mathrm{AC}}=R_{\mathrm{DC}} \frac{2 r}{4 \delta}, \\
R_{\mathrm{DC}}=\frac{l}{\sigma \pi r^{2}},
\end{gathered}
$$




$$
\delta=\frac{1}{\pi \mu_{0} \sigma f} .
$$

The coil is determined by the design specifications of the overall charging system. The coil is installed on the chassis of the EV in a limited space. So, $D_{\text {out }}$ should not take a large value. After surveying most models of cars, this value cannot exceed $350 \mathrm{~mm}$; therefore, we have chosen $D_{\text {out }}$ of $320 \mathrm{~mm}$ as the outer diameter, as shown in Figure 1.

$P$ can determine the distributed capacitance of the coil. This self-capacitance is parasitic and should be avoided. Capacitance decreases with the increase of $P$. However, if $P$ is too large, the number of turns will be limited and the coil cannot reach the required inductance. Therefore, balancing the parasitic capacitance and self-inductance, also based on our simulation results in Figure 4, we have chosen $P$ in the range of (4) and (5).

The turn number $N$ directly determines the self-inductance of the coil. And the inductance value is chosen based on the compensation circuit. In our design, based on the working frequency and circuit structure, we have calculated selfinductance around $25 \mathrm{nH}$ based on the compensation circuit. Therefore, based on the parameter tuning process, we have adopted 9 turns based on the results in Figure 5.

$W$ is the diameter of the wire, and it is determined by the current of the coil. In our design, the maximum current density is $5 \mathrm{~A} / \mathrm{m}^{2}$. At the frequency of $85 \mathrm{kHz}$, the skin depth can be calculated as $0.2285 \mathrm{~mm}$. Then, the litz wire with a diameter of $5 \mathrm{~mm}$ is selected here, which is composed of 1300 enameled wires with a diameter of $0.1 \mathrm{~mm}$.

$D_{\text {in }}$ is the inner diameter of the coil, and it can be determined by $D_{\text {out }}, P, W$, and $N$, which can be calculated as

$$
D_{\text {in }}=D_{\text {out }}-2[P(N-1)-W] .
$$

In conclusion, the parameters are brought in; because the maximum outer diameter of the receiving coil must not exceed $350 \mathrm{~mm}$, considering the size of the coil installation pallet, the maximum outer diameter of the coil is set to $320 \mathrm{~mm}$, so $D_{\text {out }}$ is $320 \mathrm{~mm}$, and $N$ is temporarily selected as 9 turns at the start of the simulation. The diameter of the litz wire can be calculated at resonance. When the frequency is $85 \mathrm{kHz}$, the skin depth is about $0.2285 \mathrm{~mm}$, and the current density $J$ is $5 \mathrm{~A} / \mathrm{m}^{2}$; the effective cross-sectional area of the wire is calculated to be $0.1 \mathrm{~cm}^{2}$. Therefore, the litz wire with a diameter of $5 \mathrm{~mm}$ is selected here, which is composed of 1300 enameled wires with a diameter of $0.1 \mathrm{~mm}$, which can well meet the design requirements. Incorporating the above parameters, it can be seen that the self-inductance of the planar spiral coil is about $23.66 \mu \mathrm{H}$.

We have adopted the LCC compensation circuit diagram shown in Figure 6. The DC-AC converter provides highfrequency $\mathrm{AC}$ power. The primary side compensation circuit generates an oscillation with a frequency of $f_{1}$, and the primary coil generates an oscillation with an oscillation frequency of $f_{2}$. The electric energy is transferred to the secondary side through the mutual inductance $M$ between the primary side and the secondary side coil. The oscillation frequency of the secondary side coil is $f_{3}$, and the oscillation

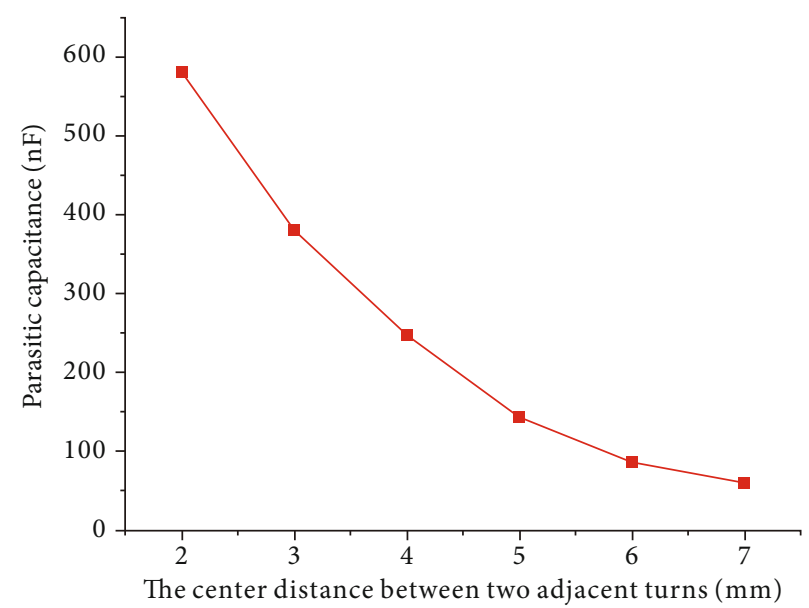

FIgURE 4: The influence of center distance between two adjacent turns to the parasitic capacitance.

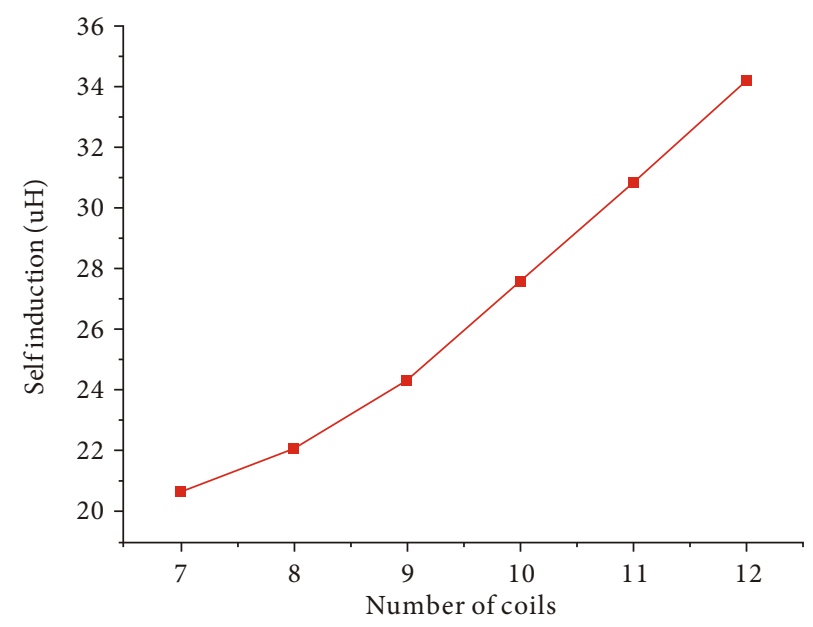

Figure 5: The influence of the number of turns to self-induction.

frequency of the secondary side resonant circuit is $f_{4}$. The AC-DC rectifier and filter capacitor convert high-frequency AC electric energy into stable DC power provided to the load. The primary and secondary sides of the LCC compensation network have additional compensation inductances and additional compensation capacitors, and the primary and secondary side compensation networks have a symmetrical structure.

According to the KVL equation, the relationship between voltage and current in the LCC compensation network can be expressed as

$$
\left[\begin{array}{c}
V_{S_{\perp} \mathrm{LCC}} \\
0 \\
0 \\
0
\end{array}\right]=\left[\begin{array}{cccc}
a & -b & 0 & 0 \\
-b & c & d & 0 \\
0 & d & e & f \\
0 & 0 & f & g
\end{array}\right]\left[\begin{array}{c}
I_{L f 1} \\
I_{1} \\
I_{2} \\
I_{L f 2}
\end{array}\right],
$$

where 


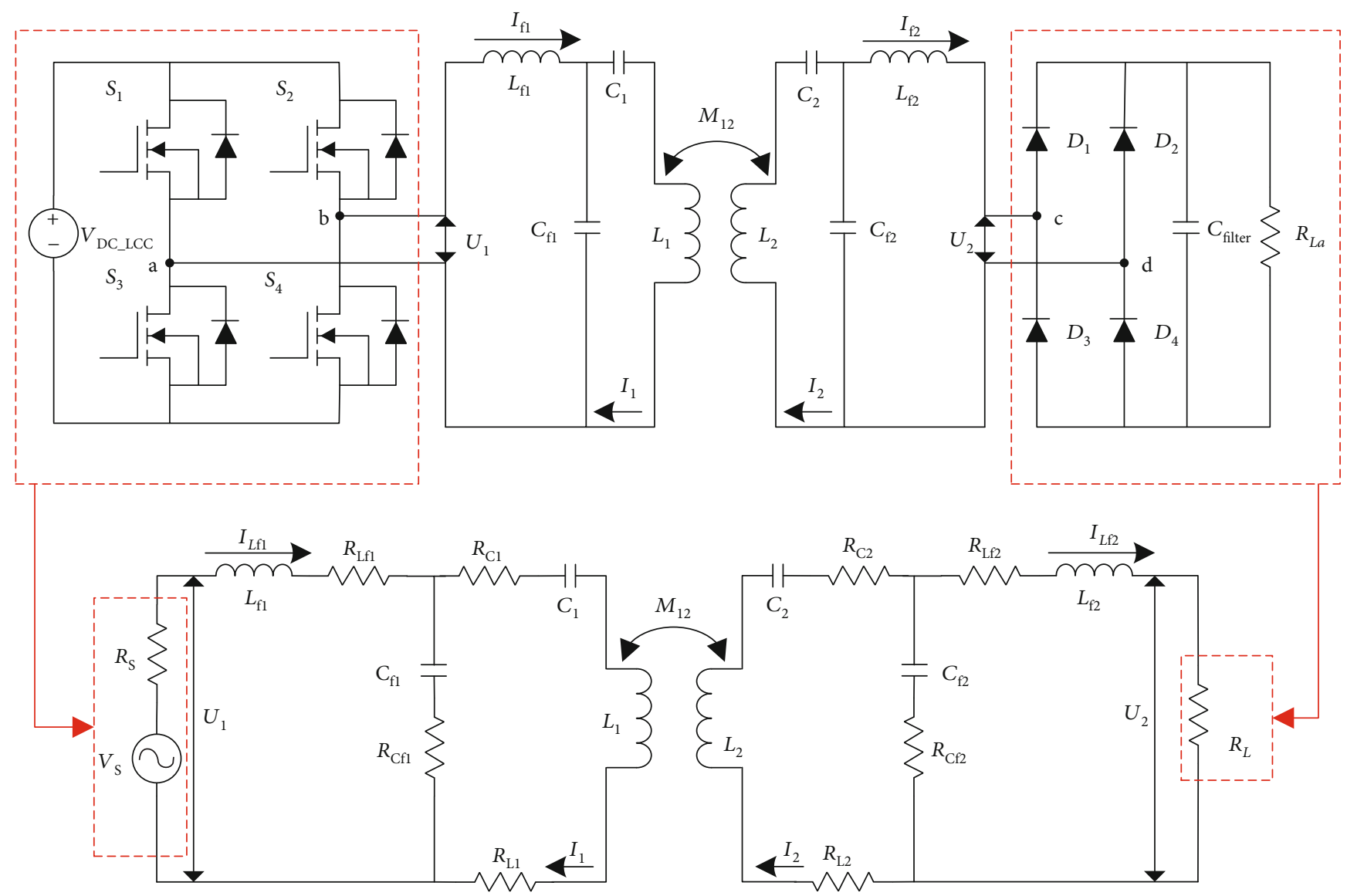

Figure 6: The LCC compensation network wireless charging system diagram.

$a=R_{S}+j \omega_{d} L_{f 1}+R_{L f 1}+\frac{1}{j \omega_{d} C_{f 1}}+R_{C f 1}$,

$b=\frac{1}{j \omega_{d} C_{f 1}}+R_{C f 1}$,

$c=j \omega_{d} L_{1}+R_{L 1}+\frac{1}{j \omega_{d} C_{1}}+R_{C 1}+\frac{1}{j \omega_{d} C_{f 1}}+R_{C f 1}$,

$d=-j \omega_{d} M_{12}$

$e=j \omega_{d} L_{2}+R_{L 2}+\frac{1}{j \omega_{d} C_{2}}+R_{C 2}+\frac{1}{j \omega_{d} C_{f 2}}+R_{C f 2}$

$f=\frac{1}{j \omega_{d} C_{f 2}}+R_{C f 2}$

$g=R_{L}+j \omega_{d} L_{f 2}+R_{L f 2}+\frac{1}{j \omega_{d} C_{f 2}}+R_{C f 2}$.

For the LCC compensation network, $I_{L f 1}$ is the output current of the primary DC-AC converter, $I_{1}$ is the current in the transmitting coil, $I_{2}$ is the current in the receiving coil, and $I_{L f 2}$ is the input current of the secondary AC-DC rectifier, and they can be calculated as

$$
\begin{gathered}
I_{L f 1}=\frac{V_{S_{-L C C}}\left(g d^{2}+c f^{2}-c e g\right)}{-b^{2} f^{2}+e g b^{2}+a g d^{2}+a c f^{2}-a c e g}, \\
I_{1}=\frac{V_{S_{-} L C C}\left(e g-f^{2}\right)}{-b^{2} f^{2}+e g b^{2}+a g d^{2}+a c f^{2}-a c e g}, \\
I_{2}=\frac{-V_{S_{-} \mathrm{LCC}} b d g}{-b^{2} f^{2}+e g b^{2}+a g d^{2}+a c f^{2}-a c e g}, \\
I_{L f 2}=\frac{V_{S_{-} \mathrm{LCC}} b d f}{-b^{2} f^{2}+e g b^{2}+a g d^{2}+a c f^{2}-a c e g} .
\end{gathered}
$$

Then, the resonant angular frequency $\omega_{r}$ can be calculated with the inductance and capacitance of the coil and the compensation network:

$\omega_{r}=\sqrt{\frac{1}{L_{f 1} C_{f 1}}}=\sqrt{\frac{1}{L_{f 2} C_{f 2}}}=\sqrt{\frac{1}{\left(L_{1}-L_{f 1}\right) C_{1}}}=\sqrt{\frac{1}{\left(L_{2}-L_{f 2}\right) C_{2}}}$.

When this condition is satisfied, the system is in resonance. The output voltage $U_{1}$ of the primary DC-AC converter and the output current $I_{L f 1}$ have the same phase, and the input voltage $U_{2}$ and the input current $I_{L f 2}$ of the secondary AC-DC rectifier have the same phase. Therefore, 
the input power and output power of the primary side of the LCC compensation network and the transmission efficiency of the primary and secondary sides are given as

$$
\begin{aligned}
P_{\text {LCC_pri }} & =V_{S_{-} \text {LCC }} I_{L f 1}, \\
P_{\text {LCC_sec }} & =I_{\text {Lf } 2} R_{L}, \\
\eta_{\text {LCC }} & =\frac{P_{\text {LCC_sec }}}{P_{\text {LCC_pri }}} .
\end{aligned}
$$

Since the LCC compensation network is designed with a symmetrical structure, the following conditions can be reached:

$$
\begin{aligned}
& L_{f 1}=L_{f 2}=L_{f}, \\
& C_{f 1}=C_{f 2}=C_{f}, \\
& L_{1}=L_{2}=L, \\
& C_{1}=C_{2}=C .
\end{aligned}
$$

When ignoring the parasitic resistance of each device in the compensation network, the primary input power and secondary output power of the LCC compensation network and the transmission efficiency of the primary and secondary sides can be simplified as

$$
\begin{aligned}
P_{\text {LCC_pri }} & =\frac{V_{S \_L C C}^{2} M_{12}^{2} R_{L}}{\omega_{r}^{2} L_{f}^{4}+R_{S} R_{L} M_{12}^{2}}, \\
P_{\text {LCC_sec }} & =\frac{V_{S \_L C C}^{2} \omega_{r}^{2} L_{f}^{4} M_{12}^{2} R_{L}}{\left(\omega_{r}^{2} L_{f}^{4}+R_{S} R_{L} M_{12}^{2}\right)^{2}}, \\
\eta_{\text {LCC }} & =\frac{\omega_{r}^{2} L_{f}^{4}}{\omega_{r}^{2} L_{f}^{4}+R_{S} R_{L} M_{12}^{2}} .
\end{aligned}
$$

It can be seen that when the system is in resonance, $M$ and $\omega$ are fixed values. When the system input voltage $V_{S_{-} \text {LCC }}$ is constant, the transmission power and transmission efficiency of the system are only related to $L_{f}$. When $L_{f}$ in the LCC type WPT system is designed to be no less than the coil mutual inductance value and the two compensation systems supply power to the same load through the same coil, the output power of the system must be the same, and the DC input voltage of the LCC type WPT system is higher, and the higher the $L_{f}$ value design, the higher the DC input voltage is required for the LCC type WPT system. Then, the lower the output current of the primary converter becomes, the lower the loss of the switching device gets. At this time, the transmission of the LCC type WPT system is enhanced. The analysis basis is that the coil impedance is divided into real and imaginary parts, and the imaginary part is zero and the real part is the maximum value when the coil is in resonance. In summary, the use of a bilateral LCC compensation circuit can improve the overall trans-

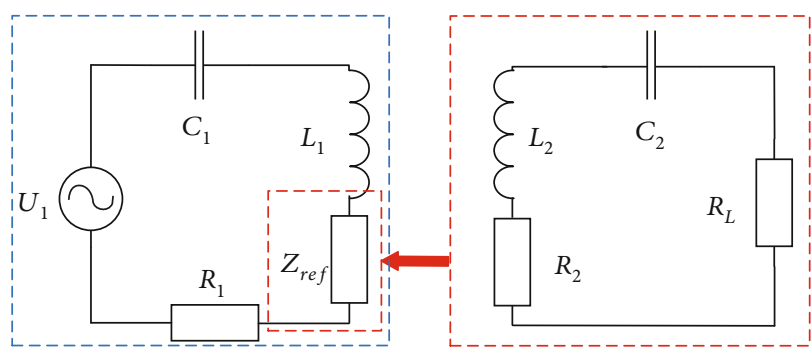

Figure 7: The model of the primary side and secondary side.

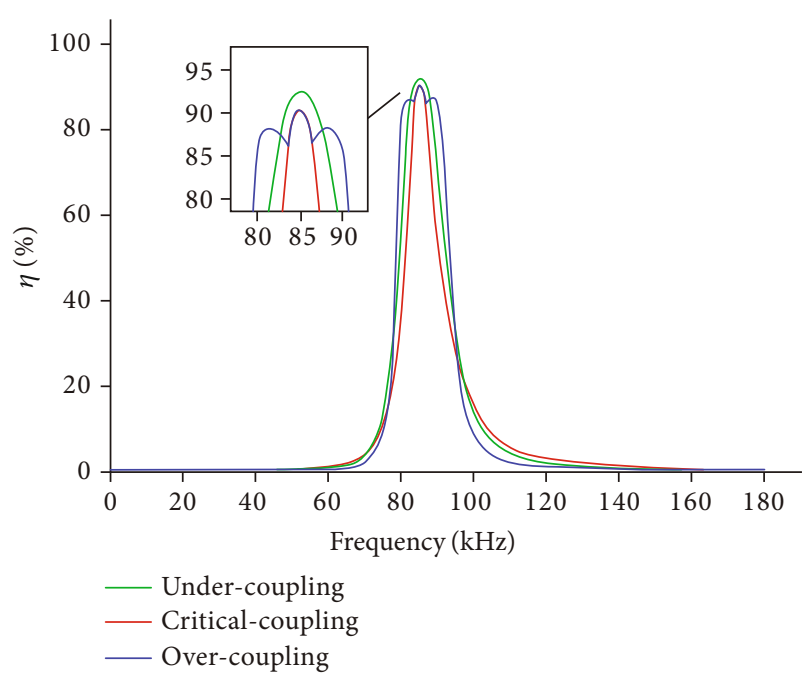

Figure 8: The transmission efficiency diagram of the system under different coupling degrees.

mission efficiency of the system and the safety and stability of power electronic devices, while also reducing the volume of the radiator required by the system and increasing the power density of the system.

Efficiency is defined as the ratio of the power received from the load vs. the power transmitted from the source:

$$
\eta=\frac{P_{\text {out }}}{P_{\text {in }}} .
$$

We have used the power analyzer HIOKI Pw6001 for output power measurement, which can calculate the realtime power based on the output voltage and current of each test point.

To show the analysis clearly, we have used the circuit model, as shown in Figure 7. After ferrite is added, the inductance of the coil is bound to change, and the coupling coefficient between the coils is bound to change when the inductance changes. In order to visually express the influence of mutual inductance on the transmission characteristics, an independent simplified model of the primary and secondary coils is established. 


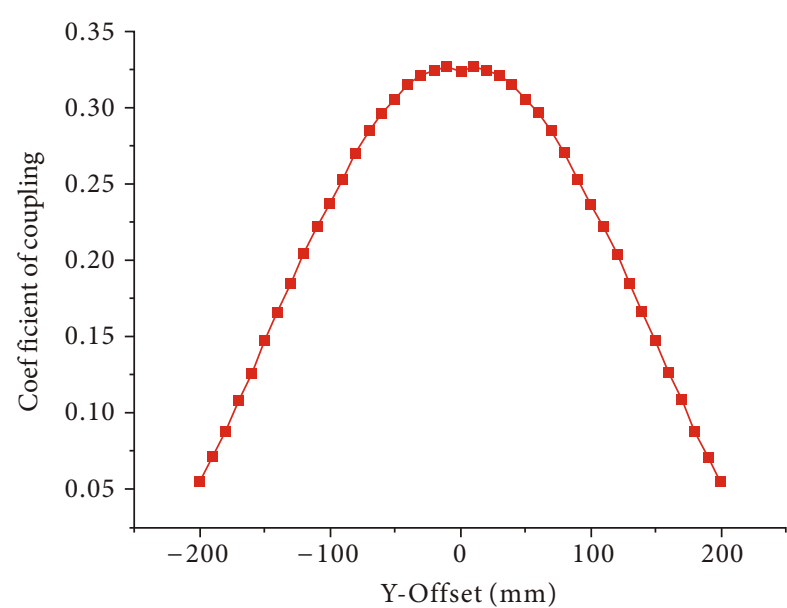

(a) Along $y$ direction

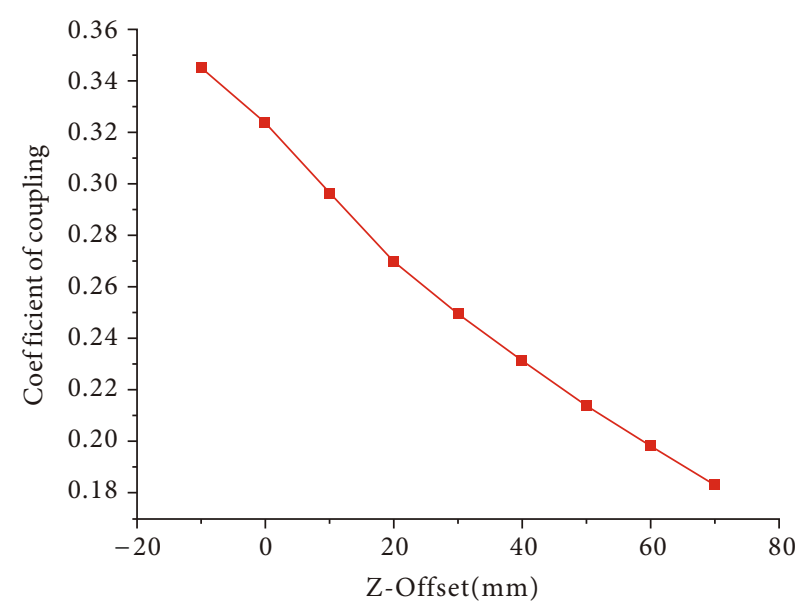

(b) Along $z$ direction

FIgURE 9: The changing of coupling coefficient under different directions of displacement.

(2)

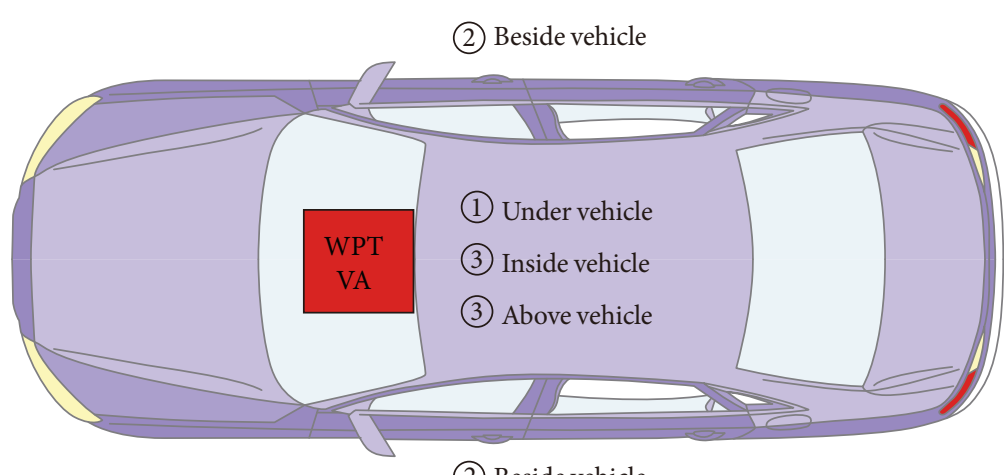

(2) Beside vehicle

(a) Top view

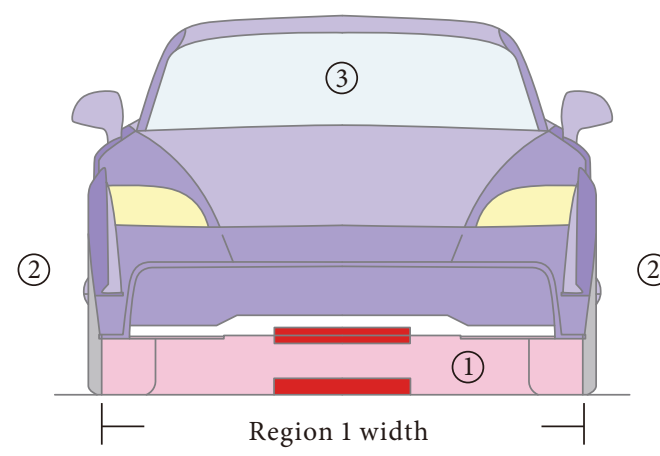

(same as lower body width)

(b) Front view

FIgURE 10: Schematic diagram of electromagnetic radiation area of electric vehicle wireless power transmission.

According to the simplified model of the original and secondary sides, the following equation can be established:

$$
\begin{aligned}
& \eta_{\text {sec }}=\frac{R_{L}}{R_{L}+R_{2}}, \\
& \eta_{\text {pri }}=\frac{\operatorname{real}\left(Z_{\text {ref }}\right)}{\operatorname{real}\left(Z_{\text {ref }}\right)+Z_{1}}, \\
& \eta_{c c}=\eta_{\text {sec }} \times \eta_{\text {pri' }} \\
& Z_{\text {ref }}=\frac{(\omega M)^{2}}{Z_{2}}, \\
& Z_{2}=R_{L}+R_{2}+j \omega L_{2}+\frac{1}{j \omega C_{2}} .
\end{aligned}
$$

The coil quality factor is defined as

$$
Q=\frac{\omega_{0} L}{R},
$$

where $\omega_{0}$ represents the natural frequency of the coil, and the difference between the frequency of the AC power supply and the natural frequency of the coil is $\Delta \omega=\omega-\omega_{0}$, which represents the degree of frequency deviation. The impedance can be transformed in combination with the definition of the coil quality factor:

$$
\begin{aligned}
Z_{1} & =R_{1}+j \omega L_{1}+\frac{1}{j \omega C_{1}}=R_{1}\left(1+\frac{j \omega L_{1}}{R_{1}}+\frac{1}{j \omega R_{1} C_{1}}\right) \\
& =R_{1}\left(1+\frac{j \omega_{0} L_{1}}{R_{1}} \cdot \frac{\omega}{\omega_{0}}+\frac{1}{j \omega_{0} R_{1} C_{1}} \cdot \frac{\omega_{0}}{\omega}\right) \\
& =R_{1}\left[1+j Q_{1}\left(\frac{\omega}{\omega_{0}}-\frac{\omega_{0}}{\omega}\right)\right] \\
& =R_{1}\left(1+j Q_{1} \xi\right),
\end{aligned}
$$

$$
Z_{2}=R_{2}+R_{L}+j \omega L_{2}+\frac{1}{j \omega C_{2}}=\left(R_{2}+R_{L}\right)\left(1+j Q_{2} \xi\right)
$$


where $\xi$ represents the detuning factor, which is defined as

$$
\xi=\left(\frac{\omega}{\omega_{0}}-\frac{\omega_{0}}{\omega}\right)
$$

Bringing the impedance transformation form into the KVL equation of the simplified model, the output power of the secondary side can be obtained as

$$
\begin{aligned}
P_{L} & =\frac{\left(\omega M U_{1}\right)^{2}}{\left[A \xi\left(Q_{1}+Q_{2}\right)\right]^{2}+\left[A-A Q_{1} Q_{2} \xi^{2}+\omega^{2} M^{2}\right]}, \\
A & =R_{2}\left(R_{2}+R_{L}\right) .
\end{aligned}
$$

Let $d P_{L} / d \xi=0$; we can solve

$$
\left\{\begin{array}{l}
\xi_{1}=0, \\
\xi_{2,3}= \pm \sqrt{\frac{A-A\left(Q_{1}+Q_{2}\right)^{2} / 2 Q_{1} Q_{2}+\omega^{2} M^{2}}{A Q_{1} Q_{2}}} .
\end{array}\right.
$$

When the condition is

$$
A-\frac{A\left(Q_{1}+Q_{2}\right)^{2}}{2 Q_{1} Q_{2}}+\omega^{2} M^{2}<0 .
$$

Then, the mutual inductance of the two coils satisfies

$$
\frac{\sqrt{A\left(Q_{1}+Q_{2}\right)^{2} / 2 Q_{1} Q_{2}-A}}{\omega}<M .
$$

There is only one solution of $\xi_{1}=0$, the output power of the system has only one extreme point, and the output power of the system increases to the resonance frequency point, which is at the undercoupling state. When the condition is satisfied as

$$
A-\frac{A\left(Q_{1}+Q_{2}\right)^{2}}{2 Q_{1} Q_{2}}+\omega^{2} M^{2}>0 .
$$

There are three solutions for $\xi$. The output power of the system begins to drop, and two extreme points will appear, and the extreme points are not at the resonance frequency, which is at the overcoupling state. When the condition is satisfied as

$$
\frac{\sqrt{A\left(Q_{1}+Q_{2}\right)^{2} / 2 Q_{1} Q_{2}-A}}{\omega}=M .
$$

The output power of the system reaches a maximum value and appears at the resonance frequency, which is at the critical coupling state. It can be seen from Figure 8 that the critical coupling transmission efficiency is the highest at the resonance frequency, and the transmission efficiency is low in the overcoupling and undercoupling states, and

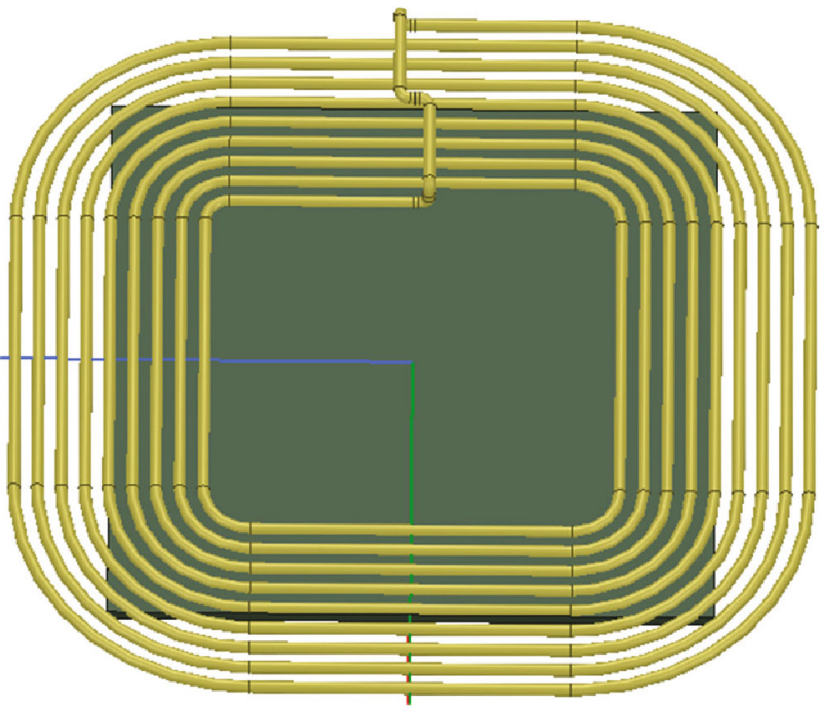

FIGURE 11: The structure of the coil.

TABLE 1: Comparison of simulated and calculated values.

\begin{tabular}{lcc}
\hline Coil parameters & Calculated value & Simulated value \\
\hline Coil inductance value $L$ & $24.348 \mu \mathrm{H}$ & $25.63 \mu \mathrm{H}$ \\
Coil resistance value $R$ & $32.148 \mathrm{~m} \Omega$ & $38.71 \mathrm{~m} \Omega$ \\
Coil capacitance value $C$ & $143.99 \mathrm{nF}$ & $132.28 \mathrm{nF}$ \\
Coil quality factor $Q$ & 404.5 & 366 \\
\hline
\end{tabular}

there are two peak points in the transmission efficiency in the overcoupling state.

Magnetically coupled wireless power transmission technology requires that the drive frequency of the system is completely equal to the self-oscillation frequency of the coil to eliminate the high-frequency inductance of the coil that severely limits the secondary side current and maximize the output power of the system. However, in the actual test process, there are many measurement errors, such as the self-inductance value of the coil and the capacitance value of the compensation capacitor. Because of the measurement error, it is difficult to ensure that the drive frequency of the system is consistent with the resonant frequency of the coil. Generally, when the coil is in the overcoupling state, when the driving frequency of the system approaches the resonance frequency of the coil, two peak output powers will appear on both sides of the resonance frequency. This phenomenon is called frequency splitting. In order to study the reasons for the existence of frequency splitting, the system input impedance is defined as

$$
\begin{aligned}
Z_{\text {in }} & =\frac{U_{1}}{I_{1}}=Z_{1}+\frac{\omega^{2} M^{2}}{Z_{2}}=R+j X, \\
R & =R_{1}+\frac{\omega^{2} M^{2}\left(R_{2}+R_{L}\right)}{\left(R_{2}+R_{L}\right)^{2}+\left(\omega L_{2}-1 /\left(\omega C_{2}\right)\right)^{2}},
\end{aligned}
$$




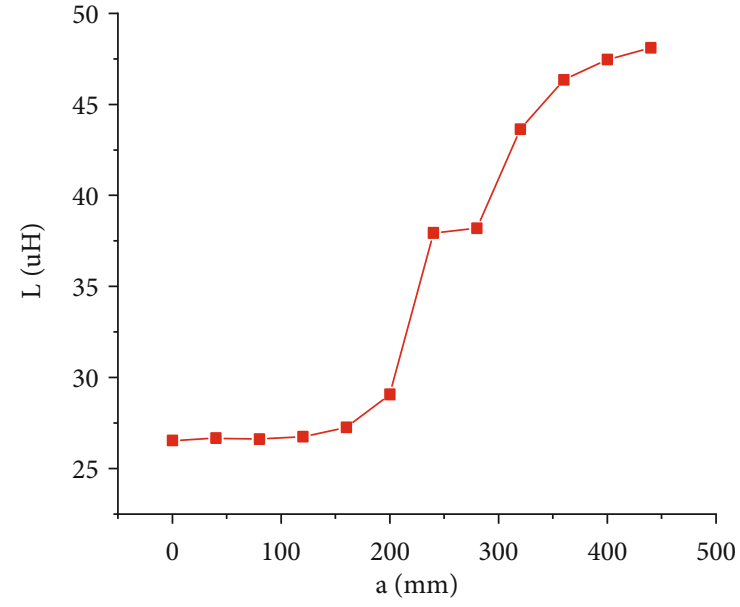

(a)

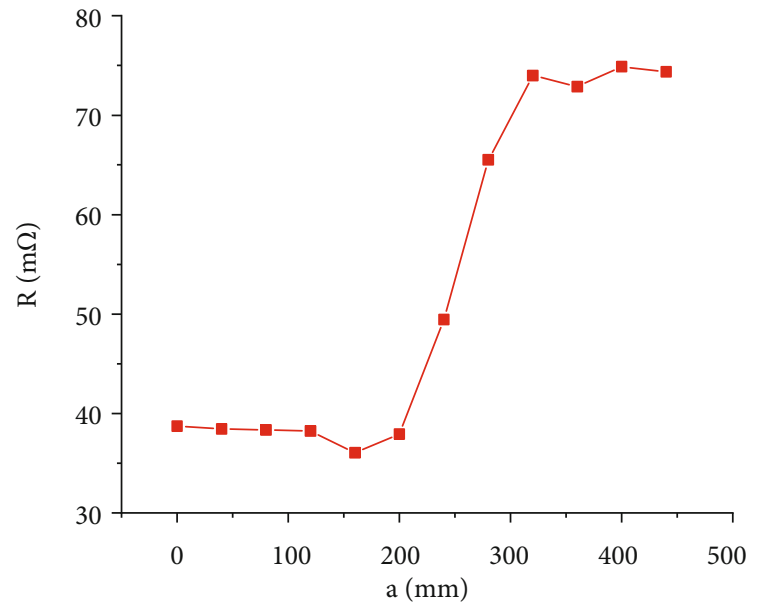

(b)

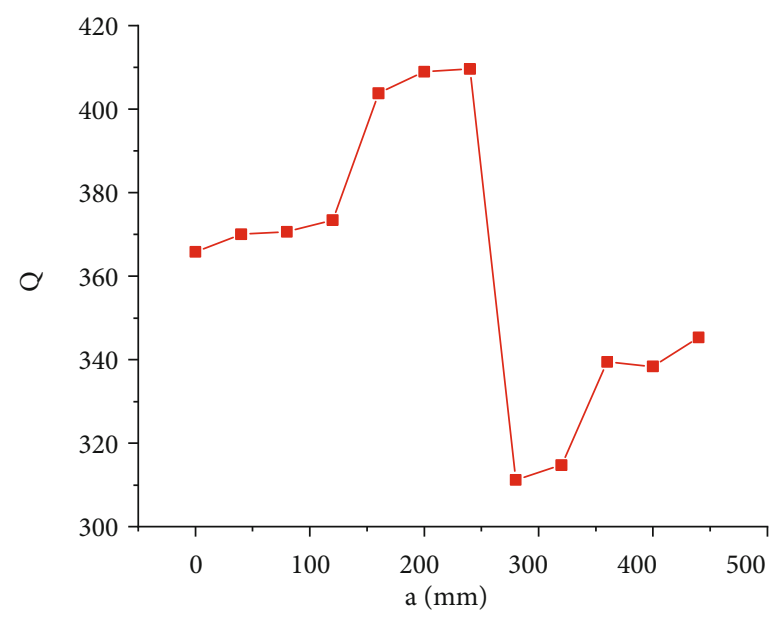

(c)

FIGURE 12: The relationship between the area of ferrite sheet and coil parameters: (a) inductance; (b) resistance; (c) quality factor.

$$
X=\omega L_{1}-\frac{1}{\omega C_{1}}-\frac{\omega^{2} M^{2}\left(\omega L_{2}-1 /\left(\omega C_{2}\right)\right)}{\left(R_{2}+R_{L}\right)^{2}+\left(\omega L_{2}-1 /\left(\omega C_{2}\right)\right)^{2}}
$$

In the overcoupling state, three values of $\omega$ can be solved by setting the imaginary part of the input impedance to 0 , which corresponds to the three extreme values of the output power. Combined with the change of the input impedance mode value, it can be seen that the input impedance mode is high at the resonance point. Therefore, the output power of the system at the resonance frequency is higher than the power at the other two extremes. This explains the cause of the frequency splitting phenomenon and the change of the system transmission power when the splitting phenomenon occurs.

Mutual coupling is very important in wireless charging systems. During the design process, we have considered the mutual coupling and have used the coupling coefficient to be the affecting factor. We can see that the displacement between the coils has a huge impact on the coupling coefficient and can lower the charging efficiency if the coils are not aligned in the right position. The simulation with the changing of the coupling coefficient under different directions of displacement is shown in Figure 9. Therefore, during wireless charging, the coils are required to align in the optimal position. We have considered this factor in the compensation circuit. So, yes indeed the coupling between the coils can be significantly affected by the magnetic material since the magnetic material creates a preferential path for the magnetic field.

Based on EV requirements as shown in Figure 10, the coil is a square wound with litz wire with a diameter of $5 \mathrm{~mm}$, and a quarter circle is replaced at the right angle of each turn of the square. The outer diameter of the coil is $320 \mathrm{~mm}$, and the inner diameter of the coil is $150 \mathrm{~mm}$, as shown in Figure 11. The turn number can be estimated to be 9 . Putting the coil size parameter into the previous formula, the following can be obtained, the coil inductance $L$ $=24.348 \mu \mathrm{H}$, the coil resistance is calculated as $R=32.148$ $\mathrm{m} \Omega$, the coil capacitance is $C=143.99 \mathrm{nF}$, so the quality factor of a single receiving coil is about 404.5. The simulation obtained the coil inductance value $L=26.53 \mu \mathrm{H}$ and the coil equivalent resistance value $R=38.71 \mathrm{~m} \Omega$; with the above analysis and calculation, the quality factor of a single coil is 


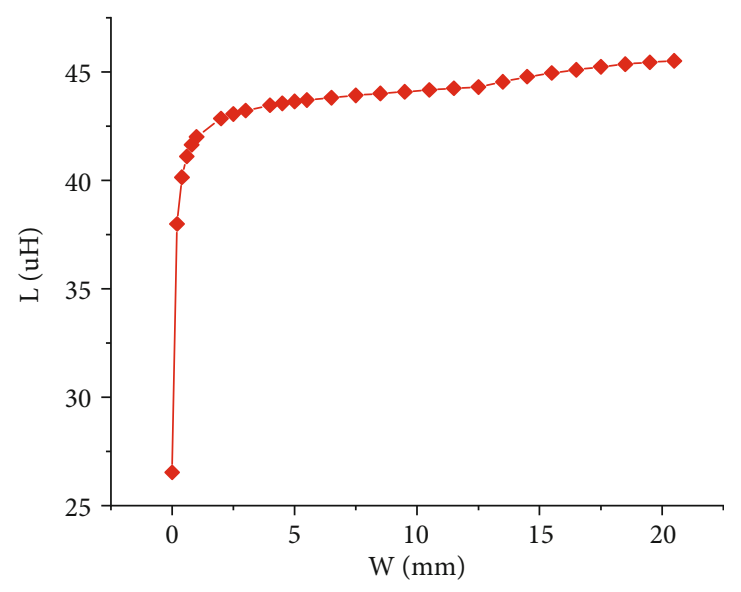

(a)

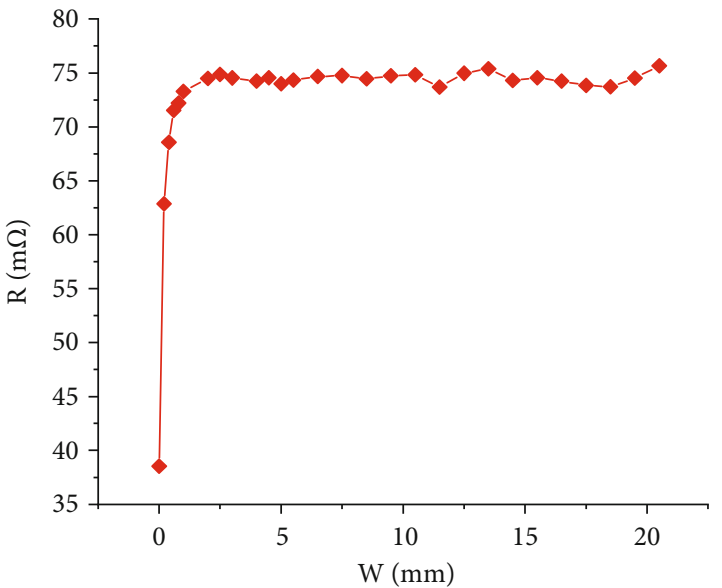

(b)

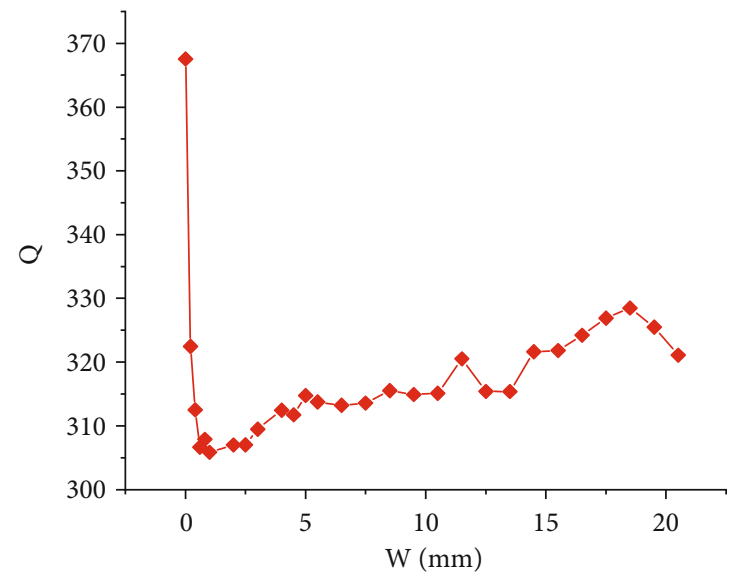

(c)

FIGURE 13: The relationship between ferrite sheet thickness and coil parameters: (a) inductance; (b) resistance; (c) quality factor.

$Q=353.61$, and the simulation analysis and calculation comparison are shown in Table 1.

There is a certain error in the calculation, but the error is small and within an acceptable range. Therefore, the simulation analysis of a single coil can verify the rationality of the previous formula.

In order to study the influence of the size of the ferrite sheet on the coil parameters, a single variable method is used to study the various parameters of the size of the ferrite sheet. First, in order to study the influence of the area of the ferrite sheet on the coil parameters, the thickness of the ferrite sheet is fixed to $5 \mathrm{~mm}$, and the ferrite sheet is close to the coil. Figure 12 shows the relationship between the area of the ferrite sheet and the coil parameters.

It can be seen from Figures 12(a) and 12(b) that as the area continues to increase, the inductance and resistance of the coil change slowly, then rise rapidly, and then gradually remain unchanged. This is because when the length is less than $160 \mathrm{~mm}$, the ferrite magnetic sheet does not cover the coil. The ferrite magnetic sheet that changes in the side length range of $0-160 \mathrm{~mm}$ has little effect on the change of the coil inductance and resistance, but as the side length of the ferrite sheet increases, the coil inductance and resistance increase rapidly. After the coil is completely covered, the area of the ferrite sheet increases again. The influence of resistance gradually weakens, so the coil inductance and resistance increase slowly. It can be seen from Figure 12(c) that the coil quality factor has two rising stages, but there is a drop close to 100 between the first stage and the second stage. This drop exists in the stage where the coil inductance grows slowly and the resistance grows rapidly from $240 \mathrm{~mm}$ to $280 \mathrm{~mm}$. At this stage, the coil inductance increases very slowly, but the coil resistance increases very quickly, which leads to a rapid increase in coil loss, so the coil quality factor declines rapidly. When the side length of the ferrite sheet is greater than $320 \mathrm{~mm}$, the coil inductance gradually increases while the coil resistance remains almost unchanged, so the coil quality factor gradually increases. Considering the various parameters of the coil, it is recommended to choose a ferrite magnet that is slightly larger than the coil area.

In order to study the influence of ferrite sheet thickness on the coil parameters, the fixed ferrite sheet area approximates the area enclosed by the outer diameter of the coil, and the ferrite is also placed close to the coil. The obtained relationship between the thickness of the ferrite sheet and the coil parameters is shown in Figure 13.

It can be seen from Figures 13(a) and 13(b) that as the thickness of the ferrite sheet increases, the coil inductance 


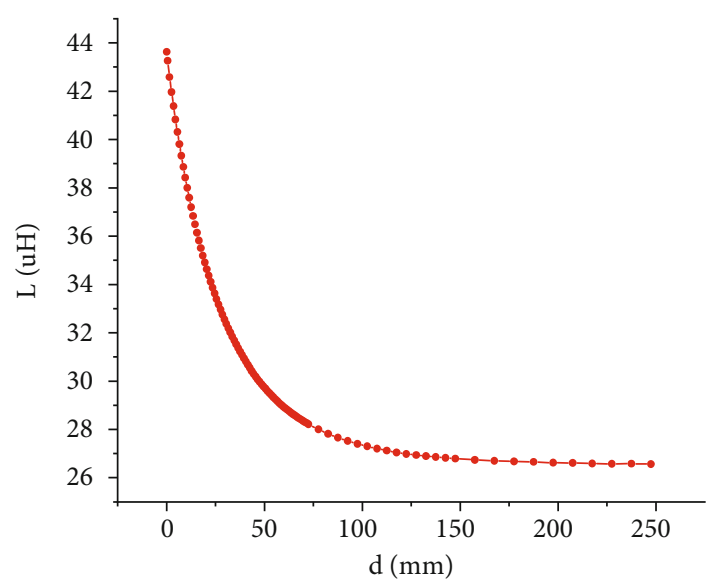

(a)

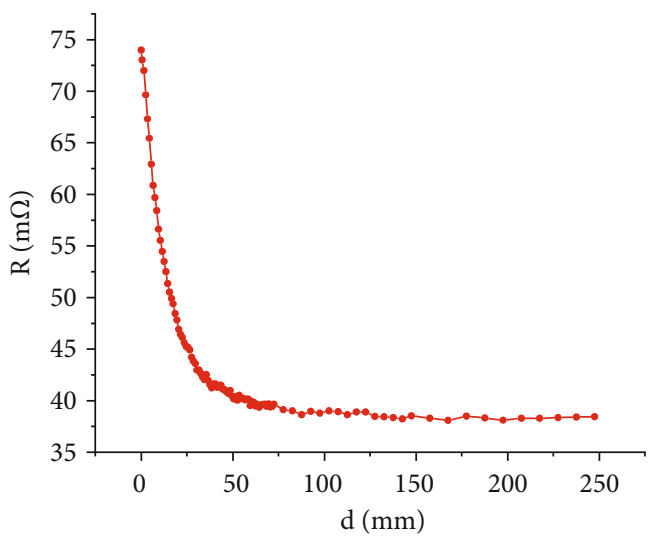

(b)

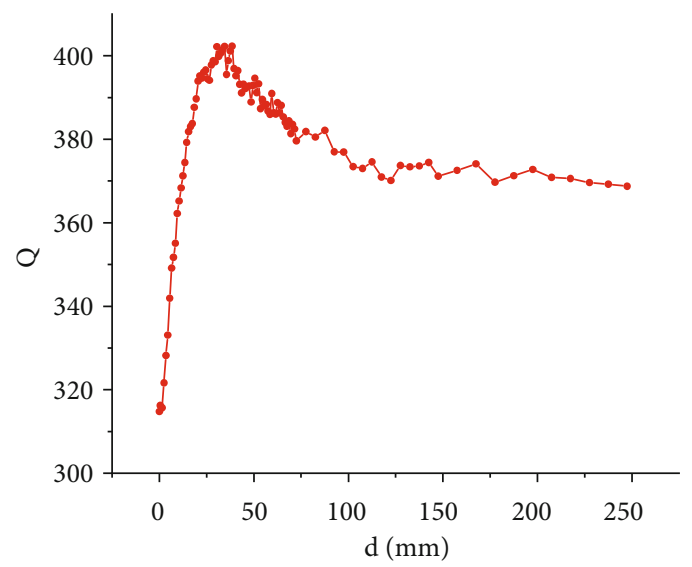

(c)

FIGURE 14: The relationship between the distance of ferrite magnet and coil parameters: (a) inductance; (b) resistance; (c) quality factor.

and coil resistance gradually increase. When the thickness of the ferrite sheet increases to a certain value, the coil inductance and resistance values slow down. This is because the thickness of the ferrite sheet is not proportional to the coil inductance and resistance, and the magnetic field intensity generated by the coil excitation is limited. Therefore, to increase the thickness of the ferrite sheet too much is redundant. From Figure 13(c), it can be seen that the coil quality factor decreases rapidly and then rises steadily as the thickness of the ferrite sheet changes. This is because the increase of ferrite also increases the loss to a certain extent. The loss caused by adding ferrite is limited, so when the quality factor drops to a certain level, the quality factor will rise as the thickness of the ferrite sheet increases. When the thickness of the ferrite sheet is increased to the length of the wire diameter, the quality factor of the coil does not change much, so it is recommended to choose a ferrite sheet with the same thickness as the wire diameter.

Finally, we have studied the influence of the distance between the ferrite sheet and the coil on the coil parameters. The thickness of the ferrite sheet is fixed to the coil wire diameter, and the area of the ferrite sheet is kept approximate to the area enclosed by the outer diameter of the coil, as shown in Figure 14.
It can be seen from Figure 14 that as the distance between the ferrite sheet and the coil increases, the inductance and resistance of the coil decrease. This is because as the distance increases, the component of the magnetic flux aggregated by the bulk magnetic sheet is weakened. When the distance is between 0 and $25 \mathrm{~mm}$, the coil inductance and resistance decrease rapidly. When the distance increases to the outer radius of the coil, the added ferrite sheet hardly has any effect on the coil. The parameter has almost no influence, so the presence of ferrite can be ignored. It can be seen from Figure 14(c) that the quality factor of the coil as a whole is a process of first increasing and then decreasing. The resistance decline trend is faster than the coil inductance decline. Combined with the definition of the coil quality factor, it can be known that the coil quality factor will increase at this time. In the distance range of $35-100 \mathrm{~mm}$, the declining trend of the coil inductance is obvious and faster than the declining trend of the coil resistance. Therefore, the quality factor of the coil will decrease within this range. After a distance of $100 \mathrm{~mm}$, the coil inductance and resistance change very slowly, so the quality factor of the coil remains basically unchanged.

From the above results, increasing the volume of the ferrite sheet can significantly increase the inductance value 


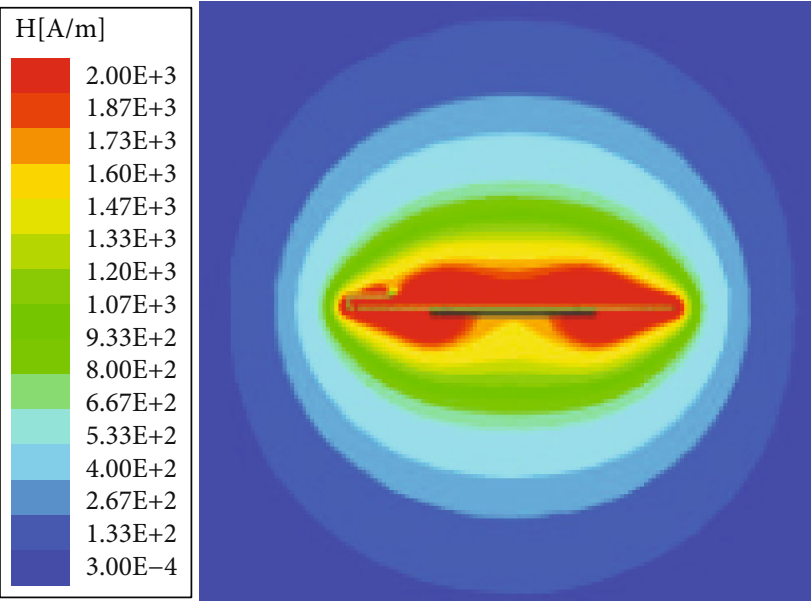

(a) Side length $=160 \mathrm{~mm}$, thickness $=5 \mathrm{~mm}$, distance $=0$
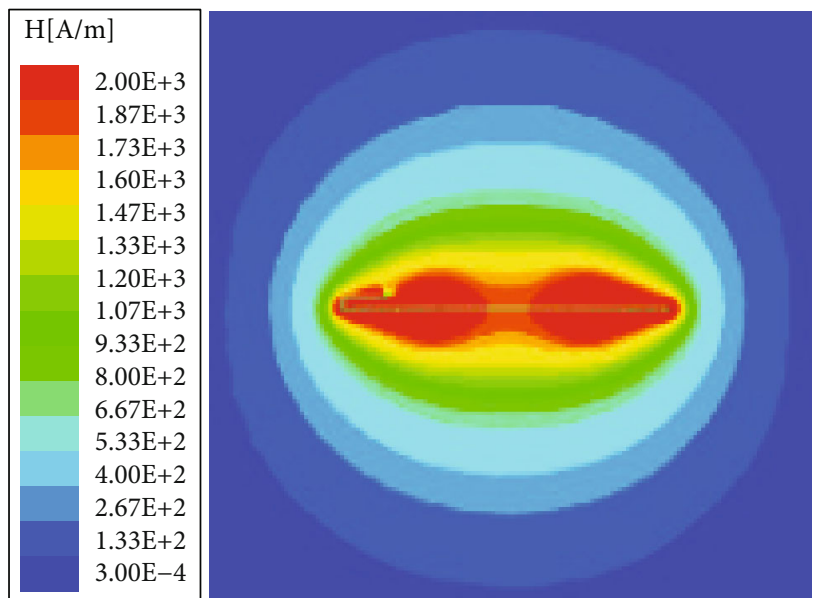

(c) Only coils, no ferrite magnets

\begin{tabular}{|c|}
\hline $\mathrm{H}[\mathrm{A} / \mathrm{m}]$ \\
$2.00 E+3$ \\
$1.87 E+3$ \\
$1.73 E+3$ \\
$1.60 E+3$ \\
$1.47 E+3$ \\
$1.33 E+3$ \\
$1.20 E+3$ \\
$1.07 E+3$ \\
$9.33 E+2$ \\
$8.00 E+2$ \\
$6.67 E+2$ \\
$5.33 E+2$ \\
$4.00 E+2$ \\
$2.67 E+2$ \\
$1.33 E+2$ \\
$3.00 E-4$ \\
\hline
\end{tabular}

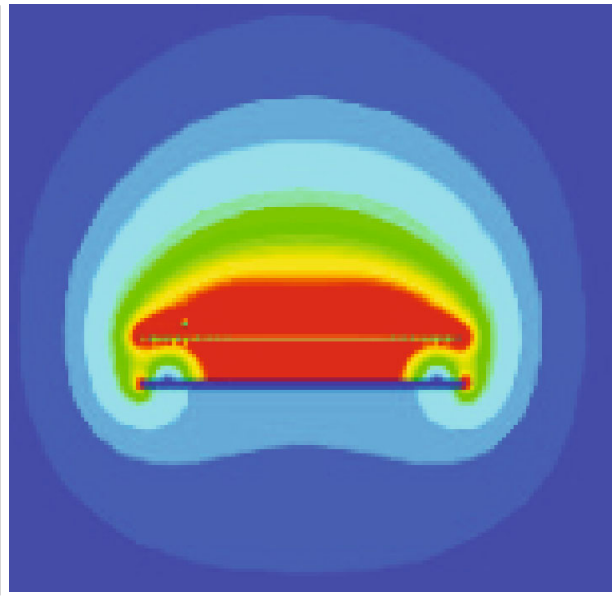

(e) Side length $=320 \mathrm{~mm}$, thickness $=5 \mathrm{~mm}$, distance $=35 \mathrm{~mm}$

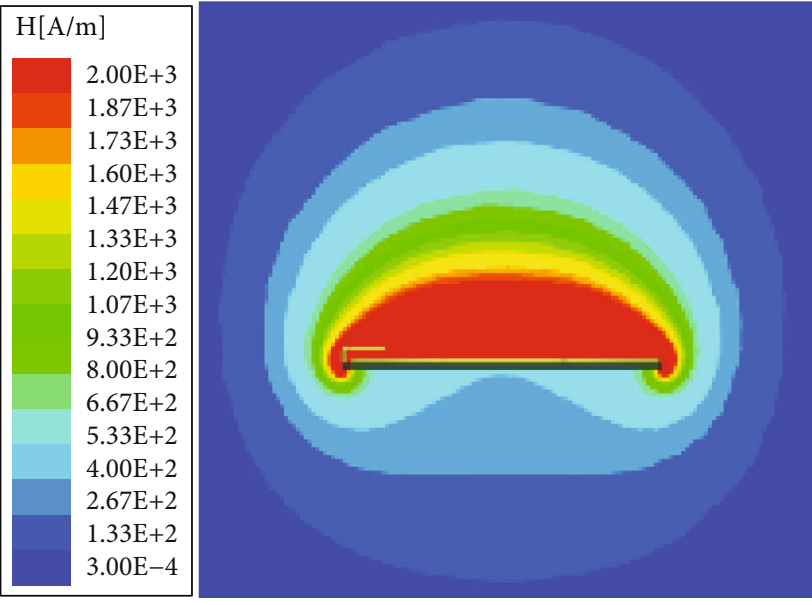

(b) Side length $=320 \mathrm{~mm}$, thickness $=5 \mathrm{~mm}$, distance $=0$

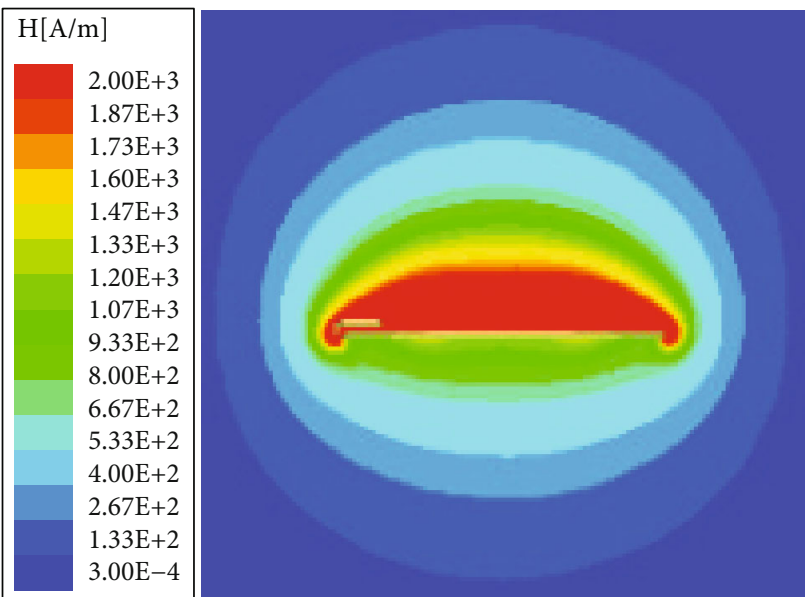

(d) Side length $=320 \mathrm{~mm}$, thickness $=0.2 \mathrm{~mm}$, distance $d=0$

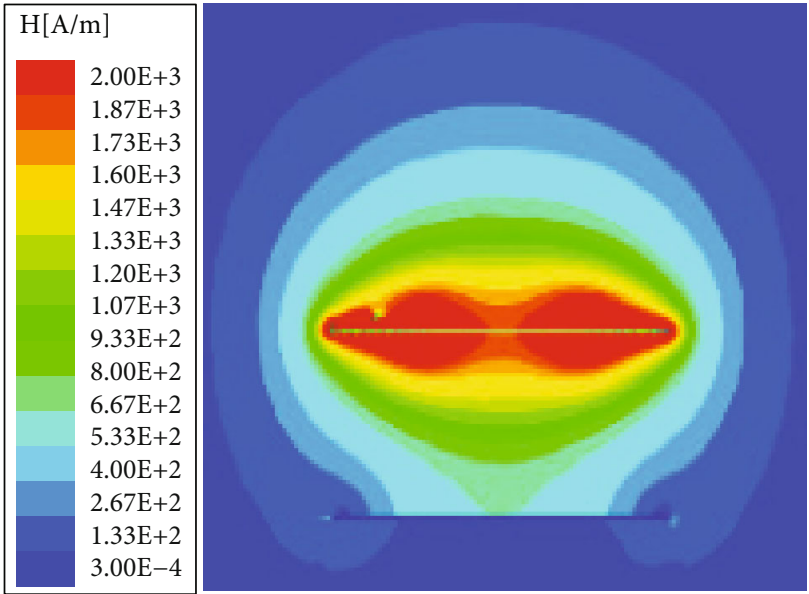

(f) Side length $=320 \mathrm{~mm}$, thickness $=5 \mathrm{~mm}$, distance $d=160 \mathrm{~m}$

FIGURE 15: The influence of ferrite magnetic sheet parameters on the magnetic field around the coil.

of the coil, but at the same time, the equivalent resistance value of the coil will also increase. But the loss will also increase, resulting in coil quality factor decrease. After placing the ferrite at a certain distance from the coil, we can consider the inductance, resistance, and other parameters of the coil, while maintaining the quality factor of the coil at a high level. So, in practical applications, it can be combined with the coil inductance and resistance to select ferrite magnets.

The strength of the magnetic field around the coil can directly indicate the coupling coefficient of the coil, and the coupling coefficient is closely related to the transmission 


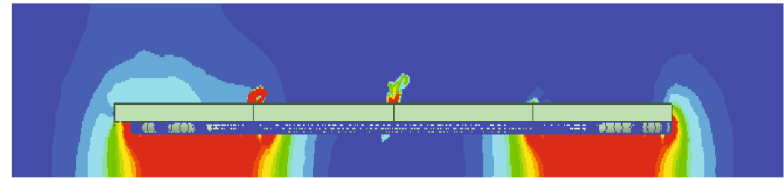

(a) Side view with ferrites in the center

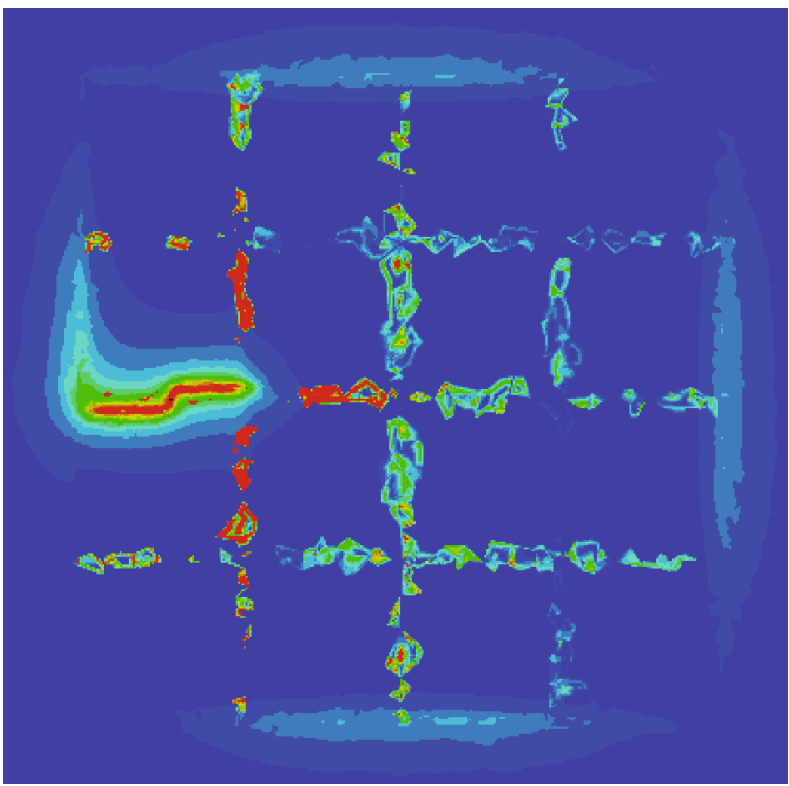

(c) Bottom view with ferrites in the center

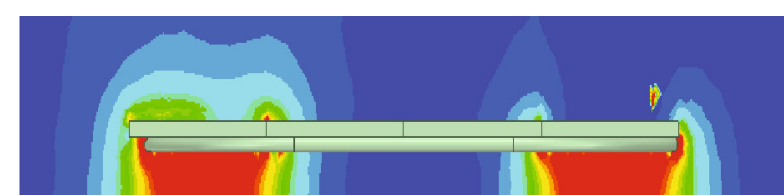

(b) Side view without ferrites in the center

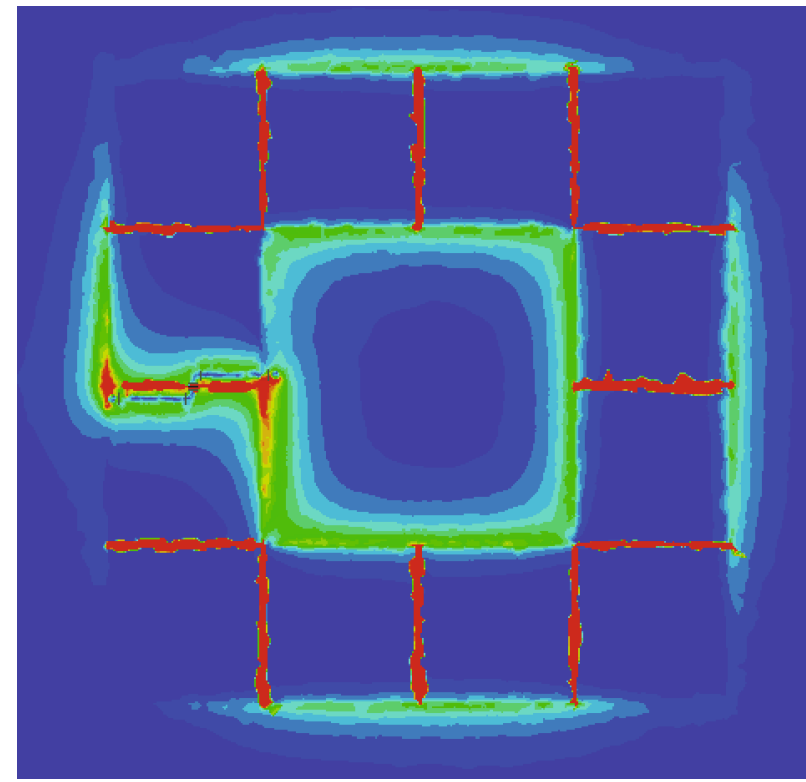

(d) Bottom view without ferrites in the center

Figure 16: The influence of ferrite magnetic sheet on magnetic shielding.

power and transmission efficiency. Therefore, in order to verify the correctness of the above analysis, the influence of the size of the ferrite magnetic sheet on the strength of the magnetic field around the coil was further analyzed, and the results are shown in Figure 15.

It can be seen that the magnetic field around a single coil is mainly distributed around the winding, because the magnetic field around a single wire is gradually weakened from near to far after the current is applied to the single wire, and the coil is not added with ferrite. The lower surrounding magnetic field is very small, which can be equivalent to the superposition of multiple wires. After adding ferrite magnets, the magnetic field on the upper part of the coil is obviously strengthened, while the magnetic field on the lower part of the coil is reduced due to the fact that the ferrite aggregates most of the magnetic flux. The magnetic field in the middle part of the coil is stronger than the two sides because the magnetic flux through the middle part is more than the magnetic flux through the two sides of the coil. By comparison, we can know that the larger the area of the ferrite sheet, the stronger the magnetic field strength on the coil, and the greater the transmission distance and coupling coefficient. The thicker the ferrite magnetic sheet, the stronger the magnetic field strength of the part of the coil, and the greater the transmission distance and coupling coefficient. After the distance between the ferrite magnetic sheet and the coil is increased, the magnetic field on the coil is significantly weakened, and the transmission distance and coupling coefficient are reduced. When the distance between the ferrite magnetic sheet and the coil is increased to $160 \mathrm{~mm}$, the magnetic field distribution around the coil is not much different from that of the nonferrite magnetic sheet.

We also have done the simulation with different permutations of ferrites. In fact, we have discovered that the shape is not a very important factor in electromagnetic field shielding as long as the ferrites are covered fully under the coil. If the ferrites are distributed only under the coil and not on the center, we can see that the magnetic field leakage will be increased, as shown in Figure 16. Since this coil is installed on the chassis, we have adopted the configuration where the ferrites are added to the center.

From the above results, increasing the area and thickness of the ferrite sheet can significantly increase the inductance of the coil and increase the magnetic field strength around the coil, but at the same time, the equivalent $\mathrm{AC}$ resistance value of the coil will also increase, and the loss will also be increased, resulting in a change in the quality factor of the coil. After placing the ferrite at a certain distance from the coil, it can take into account the inductance of the coil itself, equivalent AC resistance, and other parameters, while maintaining the quality factor of the coil at a high level, which can be in a certain range according to the actual situation. Adjust internally, but note that the distance between the ferrite magnet and the coil must not exceed the outer radius of the coil; otherwise, the designed ferrite magnet will have 


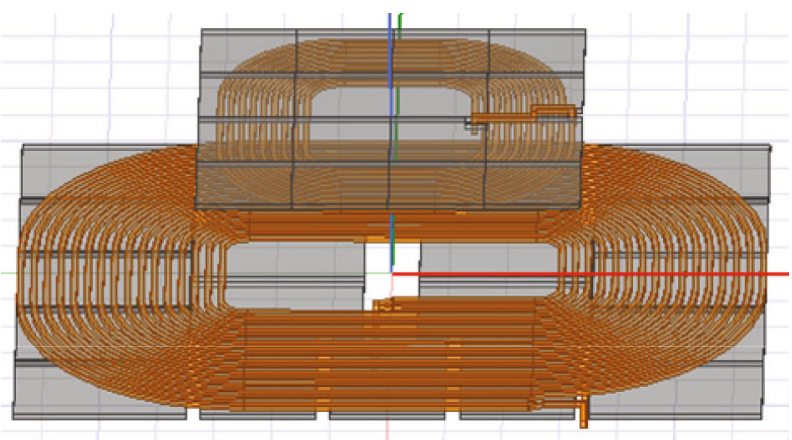

(a)

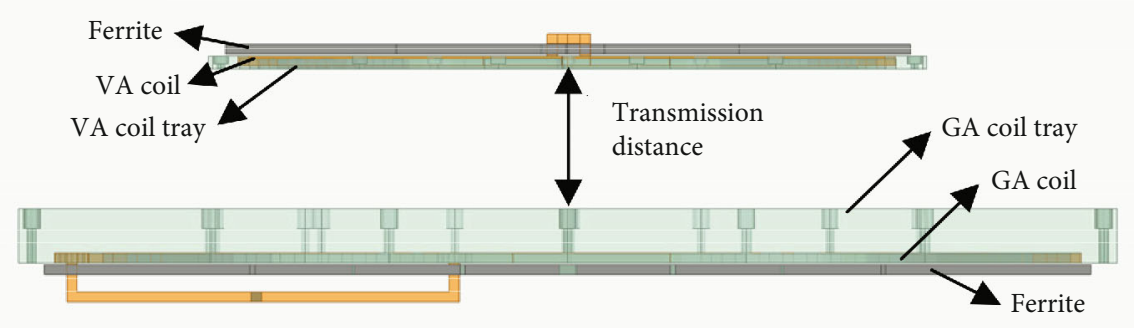

(b)

\begin{tabular}{|r|}
\hline $\mathrm{H}[\mathrm{A} / \mathrm{m}]$ \\
$2.00 \mathrm{E}+3$ \\
$1.87 \mathrm{E}+3$ \\
$1.73 \mathrm{E}+3$ \\
$1.60 \mathrm{E}+3$ \\
$1.47 \mathrm{E}+3$ \\
$1.33 \mathrm{E}+3$ \\
$1.20 \mathrm{E}+3$ \\
$1.07 \mathrm{E}+3$ \\
$9.33 \mathrm{E}+2$ \\
$8.00 \mathrm{E}+2$ \\
$6.67 \mathrm{E}+2$ \\
$5.33 \mathrm{E}+2$ \\
$4.00 \mathrm{E}+2$ \\
$2.67 \mathrm{E}+2$ \\
$1.33 \mathrm{E}+2$ \\
$3.00 \mathrm{E}-4$ \\
\hline
\end{tabular}

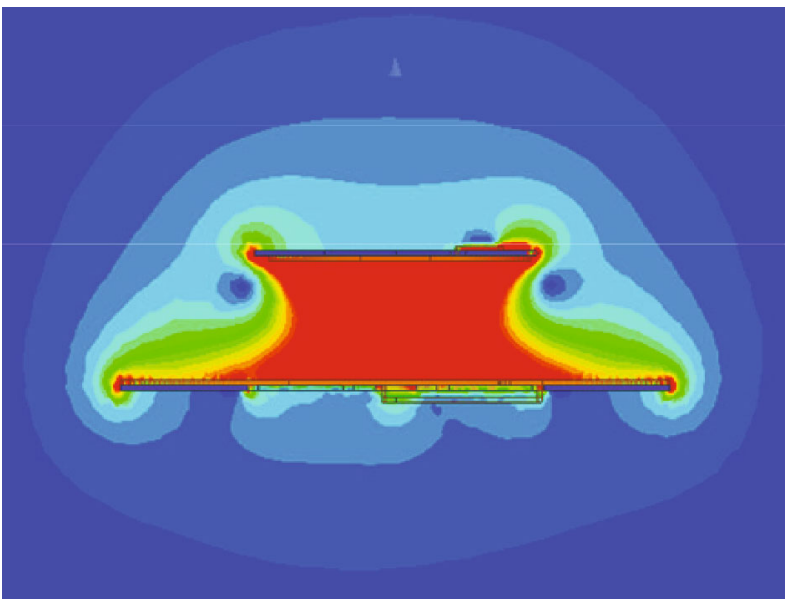

(c)

FIgURE 17: The transmitting and receiving coils: (a) 3D view; (b) side view; (c) magnetic field distribution.

little effect on the coil parameters. However, in practical applications, the ferrite magnetic sheet is not easy to install and generally considers the paste method to be placed close to the coil. The ferrite is composed of small ferrite magnetic pieces with a side length of $80 \mathrm{~mm} \times 80 \mathrm{~mm}$ arranged in 4 $\times 4$, and the magnetic piece is placed as close as possible, and the entire ferrite magnetic piece is also placed as close as possible to the coil.

After designing the transmitting and receiving coils, a simulation model is built at the condition where the two coils are $170 \mathrm{~mm}$ apart, as shown in Figures 17(a) and 17(b). Simulation analysis is performed to obtain the magnetic field distribution around the coil as shown in Figure 17(c). The simulated coupling coefficient of the two coils is 0.18151 when they are $170 \mathrm{~mm}$ apart. Combining the coupling coefficient and the inductance values of the two coils and reversing the previous assumptions to meet the output power requirements, the resonant frequency of the two coils is very close to the system resonant frequency, which meets the design specifications. It can be seen from Figure 17(c) that the magnetic field around the two coils is concentrated between the two coils because of the ferrite, and the magnetic field outside the transmission range of the coils is significantly suppressed, indicating that the designed ferrite can play a good role in the coils.

\section{Measurement Results}

In order to verify the correctness of the theoretical analysis and the feasibility of the coil design, the physical model of the coil is manufactured, and the experimental test platform of the coil is built. The coil parameters and system efficiency 


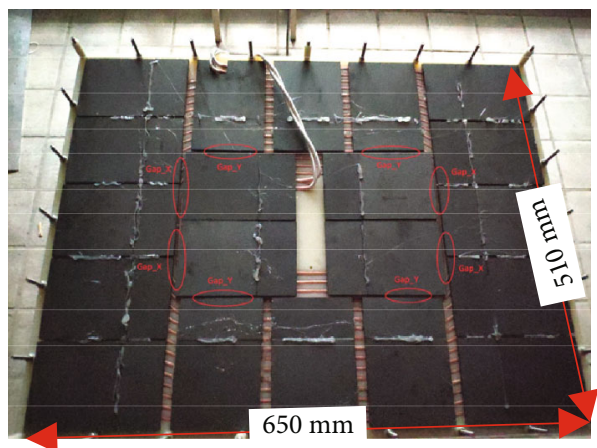

(a)

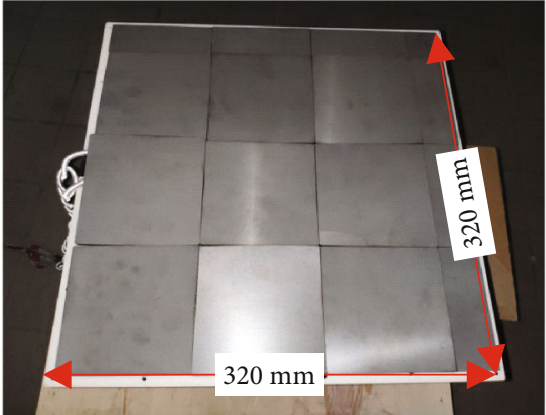

(b)

FIgURE 18: The photograph of the manufactured coils: (a) transmitting coil; (b) receiving coil.

are tested through the coil test platform. The experimental models of the transmitting coil and receiving coil are shown in Figure 18. Both the transmitting coil and the receiving coil consist of three parts: nylon support plate, coil, and ferrite layer. The size of the receiving coil nylon support plate is $350 \mathrm{~mm} \times 350 \mathrm{~mm}$, and the nylon pallet of the transmitting coil is $675 \mathrm{~mm} \times 535 \mathrm{~mm}$. The ferrite layer is realized by the combination of small $\mathrm{MnZn}$ ferrite magnetic pieces, and the pieces are stuck by glue.

In order to facilitate coil measurement, a test platform was set up, as shown in Figure 19. The coil test platform includes the following parts: receiving coil, transmitting coil, fixed frame, and offset test bench. The aluminum plate as a shielding layer can effectively confine the electromagnetic radiation area between the two coils, in order to make the size of the receiving coil and the transmitting coil after the aluminum shielding layer also within the allowable range of the design specifications. The aluminum shielding layer of the receiving coil should be $350 \mathrm{~mm} \times 350 \mathrm{~mm}$, and the aluminum shielding layer of the transmitting coil should be $680 \mathrm{~mm} \times 600 \mathrm{~mm}$.

Table 2 lists the measurement results. Because the surrounding environment may affect the measurement of various parameters of the coil, it is inevitable that there will be errors in the measurement results. The simulated and measured coil inductance values are still very close. The overall current density reduces the equivalent $\mathrm{AC}$ resistance affected by the skin effect, so the measured value is smaller than the simulated value.

In order to study the performance of the designed coil, it is necessary to apply the coil to the electric vehicle wireless charging system. According to the existing conditions in the laboratory, an electric vehicle wireless charging experimental platform was built as shown in Figure 20. The test circuit includes the high-frequency inverter circuit, the primary side compensation circuit, the rectifier circuit, the secondary side compensation circuit, and the control circuit of the electric vehicle wireless power transmission system. The coil is connected to the primary side compensation circuit, and the receiving coil is connected to the secondary side compensation circuit. Testing instruments mainly include DC power supply, resistive load, auxiliary power supply, oscilloscope, high-voltage differential probe,

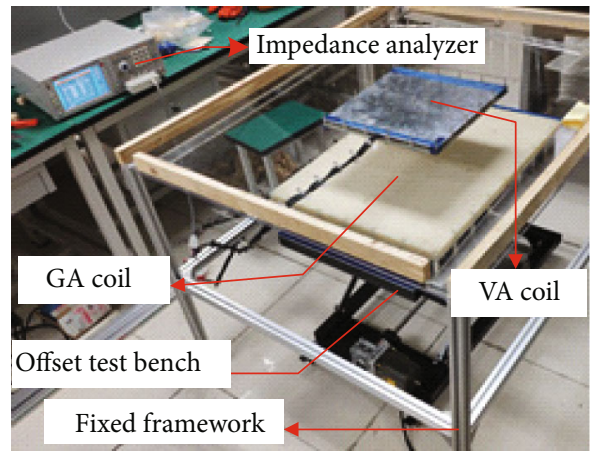

FIgURE 19: The photograph of the measurement setup.

TABle 2: Measurement data at $85 \mathrm{kHz}$.

\begin{tabular}{lcc}
\hline Parameter & Transmitting coil & Receiving coil \\
\hline Self-inductance $(\mu \mathrm{H})$ & 45.78 & 44.37 \\
Resistance $(\mathrm{m} \Omega)$ & 55.4 & 58.8 \\
Mutual inductance $(\mu \mathrm{H})$ & \multicolumn{2}{c}{10.26} \\
\hline
\end{tabular}

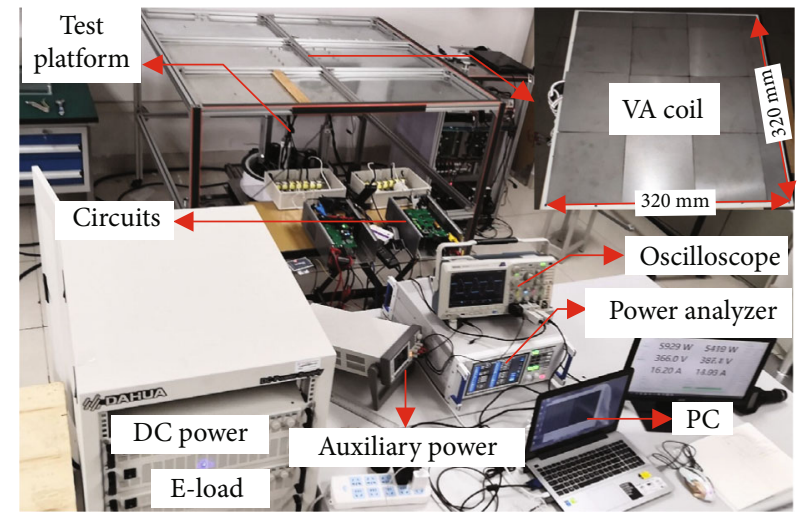

FIgURE 20: The photograph of the wireless charging system measurement platform. 


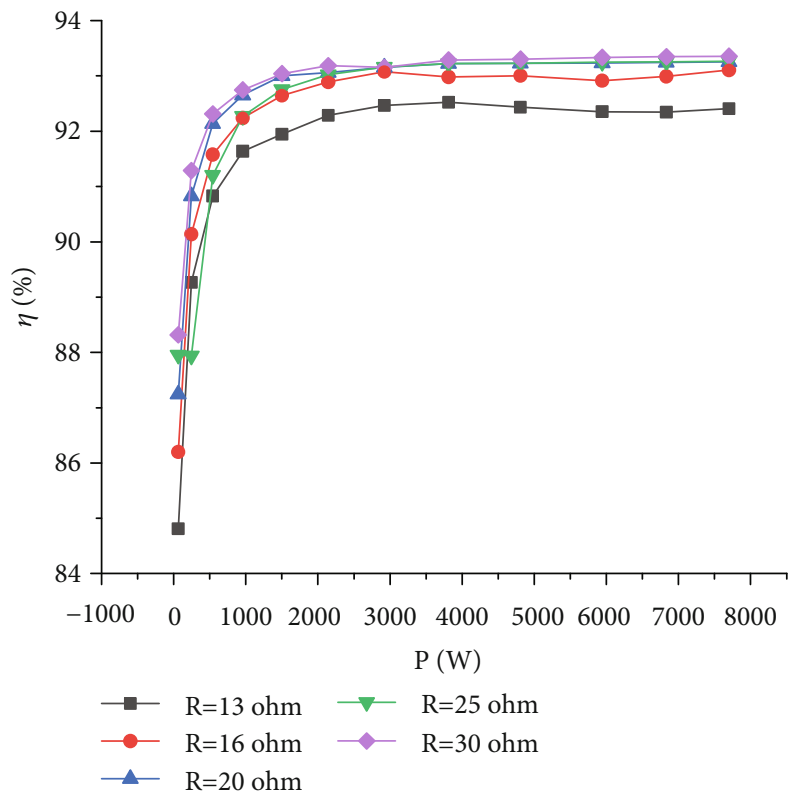

Figure 21: The measured transmission efficiency of WPT system under different load conditions.

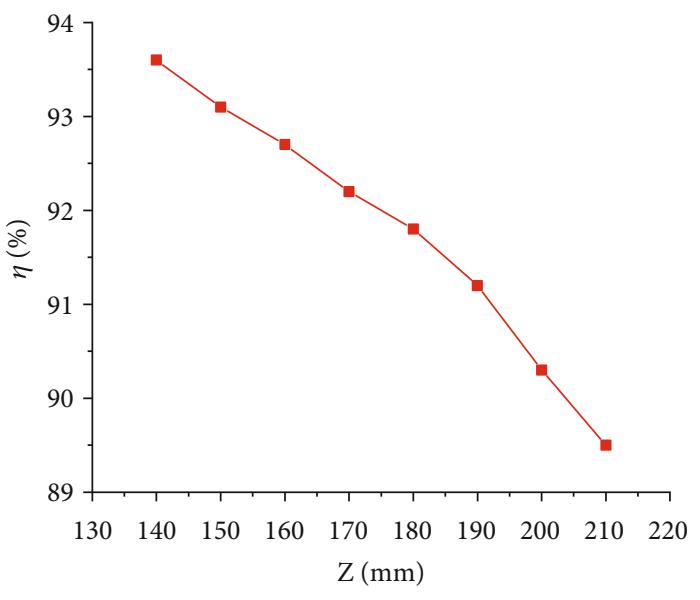

(a)

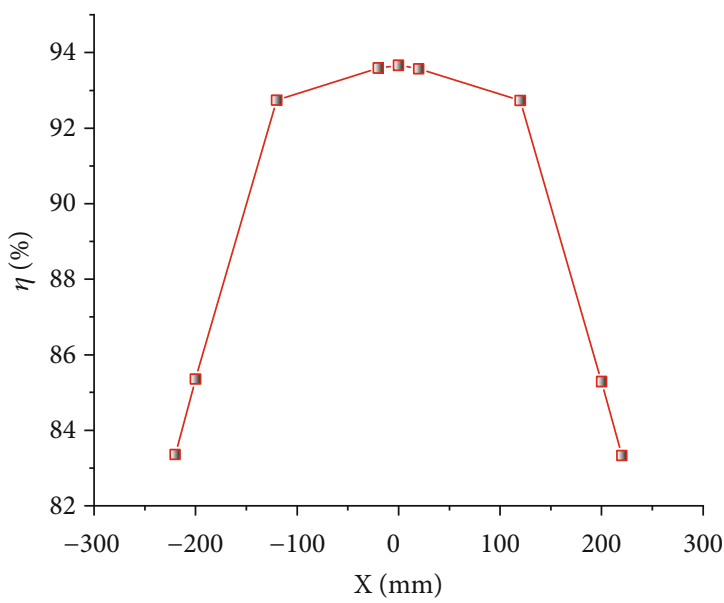

(b)

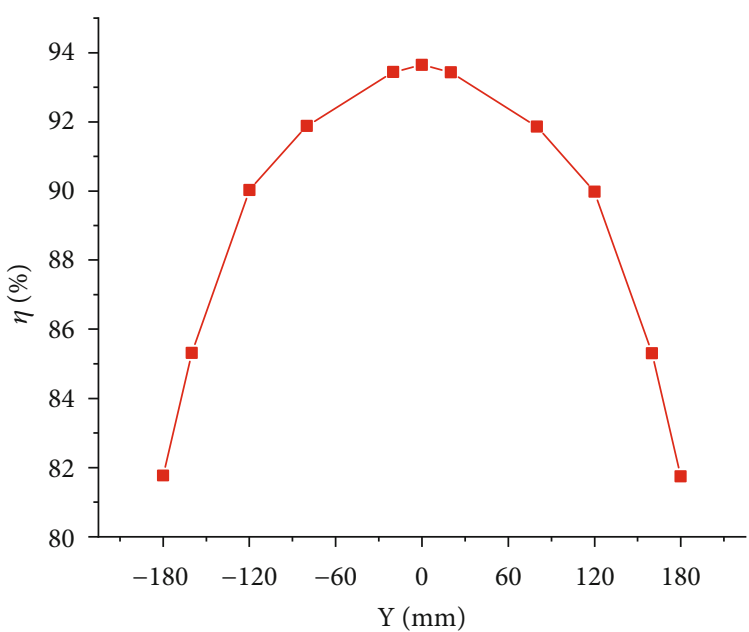

(c)

FIGURE 22: The system efficiency with different movements of the $\eta$ receiving coil along (a) $z$-axis; (b) $x$-axis; (c) $y$-axis. 
TABle 3: Performance comparison.

\begin{tabular}{|c|c|c|c|c|c|c|}
\hline $\begin{array}{l}\text { Magnetically coupled } \\
\text { structure }\end{array}$ & Size $(\mathrm{mm})$ & $\begin{array}{c}\text { Distance } \\
(\mathrm{mm})\end{array}$ & $\begin{array}{l}\text { Frequency } \\
(\mathrm{kHz})\end{array}$ & $\begin{array}{c}\text { Power } \\
(\mathrm{kW})\end{array}$ & $\begin{array}{c}\text { Efficiency } \\
(\%)\end{array}$ & The output with horizontal offset \\
\hline$[20]$ & $770 \times 410$ & 200 & 20 & 6.6 & - & $\begin{array}{l}\text { At } 140 \mathrm{~mm} \text { offset, the power is } \\
4.4 \mathrm{~kW}\end{array}$ \\
\hline$[21]$ & $770 \times 410$ & 125 & 20 & 6.4 & - & $\begin{array}{l}\text { At } 140 \mathrm{~mm} \text { offset, the power is } \\
3.8 \mathrm{~kW}\end{array}$ \\
\hline$[22]$ & $\begin{array}{l}\text { GA } 1100 \times 900 \\
\text { VA } 800 \times 300\end{array}$ & 150 & 20 & 15 & 75.00 & $\begin{array}{l}\text { At } 200 \mathrm{~mm} \text { offset, the power is } \\
5 \mathrm{~kW}\end{array}$ \\
\hline$[23]$ & $\begin{array}{l}\text { GA } 800 \times 800 \\
\text { VA } 600 \times 600\end{array}$ & 200 & 100 & 6.6 & 95.57 & - \\
\hline$[24]$ & Diameter 420 & 100 & 85 & 1.0 & 91.30 & - \\
\hline$[25]$ & $600 \times 600$ & 150 & 150 & 10 & $>80.00$ & $\begin{array}{l}\text { At } 200 \mathrm{~mm} \text { offset, the efficiency is } \\
\qquad 2.3 \%\end{array}$ \\
\hline This paper & $\begin{array}{l}\text { VA } 650 \times 510 \\
\text { GA } 320 \times 320\end{array}$ & 170 & 85 & 6 & 93.6 & $\begin{array}{l}\text { At } 200 \mathrm{~mm} \text { offset, the efficiency is } \\
\qquad 85 \%\end{array}$ \\
\hline
\end{tabular}

current test loop, power analyzer, and control computer. The DC power supply provides a maximum input power of $6 \mathrm{~kW}$, and the load resistance simulates the internal resistance of the car battery.

The measured transmission efficiency of the two coils should be between $140 \mathrm{~mm}$ and $210 \mathrm{~mm}$ to achieve a maximum transmission efficiency of $93 \%$. In order to verify whether the coil design meets the design indicators and find the optimal load size of the system, we have adjusted the distance between the two coils to $140 \mathrm{~mm}$, the input voltage value of the DC power supply, and the MOS tube in the high-frequency inverter circuit through the DSP controller of the control circuit. The coil drive frequency is $85 \mathrm{kHz}$, and the transmission efficiency of the test system under different load conditions is shown in Figure 21. It can be seen that the transmission efficiency of the WPT system is higher than $92 \%$ when the input is $6 \mathrm{~kW}$ under different load conditions. At the same time, under the condition of the optimal load of $30 \Omega$, the output of $5616 \mathrm{~W}$ can be achieved when the input is $6 \mathrm{~kW}$, and the highest transmission efficiency of $93.6 \%$ is achieved.

In order to verify whether the two coils can achieve a maximum transmission efficiency of $85 \%$ when the radius of the receiving coil is offset, the efficiency $\eta$ of the test system under the optimal load of $30 \Omega$ varies with the movement of the receiving coil on the $z$-axis, $x$-axis, and $y$-axis, respectively. Figure 22(a) shows that when the receiving coil moves along the $z$-axis, the system transmission efficiency becomes lower as the distance gets larger. Figures 22(b) and 22(c) show the change in system transmission efficiency as the receiving coil moves along the $x$-axis and $y$-axis, respectively. It can be seen that efficiency becomes lower as the offset gets larger, whether it is on the $x$-axis or $y$-axis. The maximum efficiency point occurs when there is no offset. On the $x$-axis, only when the positive or negative offset distance is greater than $200 \mathrm{~mm}$, the system transmission efficiency is less than $85 \%$. On the $y$-axis, in the short outer diameter of the transmitter coil, only when the positive or negative offset is greater than $160 \mathrm{~mm}$, the system transmission efficiency is less than $85 \%$. Through calculation, when the moving range of the receiving coil is within $200 \mathrm{~cm} \times$ $160 \mathrm{~cm}$, the attenuation of $\eta$ is less than $8 \%$. The experimental results are consistent with the previous analysis.

We have compared the performances with the coils in some other literatures, as shown in Table 3. It can be seen that the size of the coil designed in this paper is very small, and the transmission power meets the requirements of the comparable power level, the transmission efficiency is high, and the offset capability is strong. The coil structure designed in this article is simple and easy to install.

\section{Conclusion}

This paper designs a pair of transmitting and receiving coils with asymmetrical structures. During the design process, some parasitic parameters have been taken into consideration. Based on the simulated and measured results, our designed coils have achieved compact size, high efficiency, and strong offset capability compared with many coils in other literatures. Our proposed coils can be applied in modern high-power EVs.

\section{Data Availability}

Data is available on request. The corresponding author Xin Cao can be contacted to request the data. To request the data, please contact caoxin@swust.edu.cn.

\section{Conflicts of Interest}

The authors declare that they have no conflicts of interest.

\section{Acknowledgments}

This paper was funded by the Doctoral Foundation of Southwest University of Science and Technology, grant numbers 20zx7121 and 19zx7156, and Industry-University Cooperation Collaborative Education Project of Ministry of Education, grant number 202101097010. 


\section{References}

[1] J. T. Boys and J. R. Lee, "Power quality with green energy, DDC, and inductively powered EV's," in 2011 IEEE 33rd International Telecommunications Energy Conference (INTELEC), pp. 1-8, Amsterdam, Netherlands, October 2011.

[2] M. Budhia, G. Covic, and J. Boys, "A new IPT magnetic coupler for electric vehicle charging systems," in IECON 2010 36th Annual Conference on IEEE Industrial Electronics Society, pp. 2487-2492, Glendale, AZ, USA, November 2010.

[3] J. R. Lee, J. T. Boys, and G. A. Covic, "Improved grid dynamics using a localized demand control system," IEEE Transactions on Smart Grid, vol. 5, no. 6, pp. 2748-2756, 2014.

[4] Y. Nagatsuka, N. Ehara, Y. Kaneko, S. Abe, and T. Yasuda, "Compact contactless power transfer system for electric vehicles," in The 2010 International Power Electronics Conference - ECCE ASIA, pp. 807-813, Sapporo, Japan, June 2010.

[5] H. Takanashi, Y. Sato, Y. Kaneko, S. Abe, and T. Yasuda, "A large air gap $3 \mathrm{~kW}$ wireless power transfer system for electric vehicles," in 2012 IEEE Energy Conversion Congress and Exposition (ECCE), pp. 269-274, Raleigh, NC, USA, September 2012.

[6] R. Shimizu, Y. Kaneko, and S. Abe, "A new he core transmitter of a contactless power transfer system that is compatible with circular core receivers and H-shaped core receivers," 2013 $3 r d$ International Electric Drives Production Conference (EDPC), pp. 1-7, Nuremberg, Germany, October 2013.

[7] I. Fujita, T. Yamanaka, Y. Kaneko, S. Abe, and T. Yasuda, "A $10 \mathrm{~kW}$ transformer with a novel cooling structure of a contactless power transfer system for electric vehicles," in 2013 IEEE Energy Conversion Congress and Exposition, pp. 3643-3650, Denver, CO, USA, September 2013.

[8] M. Budhia, G. A. Covic, and J. T. Boys, "Design and optimization of circular magnetic structures for lumped inductive power transfer systems," IEEE Transactions on Power Electronics, vol. 26, no. 11, pp. 3096-3108, 2011.

[9] M. Budhia, J. T. Boys, G. A. Covic, and C. Y. Huang, "Development of a single-sided flux magnetic coupler for electric vehicle IPT charging systems," IEEE Transactions on Industrial Electronics, vol. 60, no. 1, pp. 318-328, 2013.

[10] A. Zaheer, H. Hao, G. A. Covic, and D. Kacprzak, "Investigation of multiple decoupled coil primary pad topologies in lumped IPT systems for interoperable electric vehicle charging," IEEE Transactions on Power Electronics, vol. 30, no. 4, pp. 1937-1955, 2015.

[11] A. Zaheer, D. Kacprzak, and G. A. Covic, "A bipolar receiver pad in a lumped IPT system for electric vehicle charging applications," in 2012 IEEE Energy Conversion Congress and Exposition (ECCE), pp. 283-290, Raleigh, NC, USA, September 2012.

[12] S. Kim, A. Zaheer, G. Covic, and J. Boys, "Tripolar pad for inductive power transfer systems," in IECON 2014 - 40th Annual Conference of the IEEE Industrial Electronics Society, pp. 3066-3072, Dallas, TX, USA, October 2014.

[13] A. Kamineni, G. A. Covic, and J. T. Boys, "Analysis of coplanar intermediate coil structures in inductive power transfer systems," IEEE Transactions on Power Electronics, vol. 30, no. 11, pp. 6141-6154, 2015.

[14] J. Lee, H. Shen, and K. Lee, "Design and implementation of weaving-type pad for contactless EV inductive charging system," IET Power Electronics, vol. 7, no. 10, pp. 2533-2542, 2014.
[15] L. Wu, B. Zhang, and J. Zhou, "Efficiency improvement of the parity-time-symmetric wireless power transfer system for electric vehicle charging," IEEE Transactions on Power Electronics, vol. 35, no. 11, pp. 12497-12508, 2020.

[16] S. Varikkottil and J. L. F. Daya, "High-gain LCL architecture based IPT system for wireless charging of EV," IET Power Electronics, vol. 12, no. 2, pp. 195-203, 2019.

[17] J. He, H. Yang, H. J. Huang, and T. Q. Tang, "Impacts of wireless charging lanes on travel time and energy consumption in a two-lane road system," Physica A: Statistical Mechanics and its Applications, vol. 500, pp. 1-10, 2018.

[18] Q. Ji, S. M. Parvasi, S. C. M. Ho, M. Franchek, and G. Song, "Wireless energy harvesting using time reversal technique: an experimental study with numerical verification," Journal of Intelligent Material Systems and Structures, vol. 28, no. 19, pp. 2705-2716, 2017.

[19] R. W. Erickson and D. Maksimovic, Fundamentals of Power Electronics, Springer Science \& Business Media, Heidelberg, Germany, 2007.

[20] J. Chen, S. Li, S. Chen, S. He, and Z. Shi, "Q-charge: a quadcopter-based wireless charging platform for large-scale sensing applications," IEEE Network, vol. 31, no. 6, pp. 5661, 2017.

[21] Z. Fu, L. Li, X. Liang, Q. Zhu, and Z. Cheng, "Thermal management optimization for a wireless charging system of electric vehicle with phase change materials," E3S Web of Conferences, vol. 118, p. 02066, 2019.

[22] H. Liu, L. Tan, X. Huang, and D. Czarkowski, "Power stabilization based on asymmetric transceiver in dynamic wireless charging system with short-segmented transmitting coils for inspection robots," Energies, vol. 11, no. 11, p. 3005, 2018.

[23] H. Zeng, X. Wang, and F. Z. Peng, "High power density Zsource resonant wireless charger with line frequency sinusoidal charging," IEEE Transactions on Power Electronics, vol. 99, pp. 10148-10156, 2018.

[24] A. Hariri, "A bilateral decision support platform for public charging of connected electric vehicles," IEEE Transactions on Vehicular Technology, vol. 68, no. 1, pp. 129-140, 2019.

[25] Z. Yang, Y. Chen, D. Yang et al., "Research on parameter optimization of double-D coils for electric vehicle wireless charging based on magnetic circuit analysis," IEICE Electronics Express, vol. 17, no. 7, 2020. 